\title{
Importance of thermal effects and sea surface roughness for offshore wind resource assessment
}

Lange, B.; Larsen, Søren Ejling; Højstrup, Jørgen; Barthelmie, R.J.

Published in:

Journal of Wind Engineering \& Industrial Aerodynamics

Link to article, DOI:

10.1016/j.jweia.2004.05.005

Publication date:

2004

Document Version

Early version, also known as pre-print

Link back to DTU Orbit

Citation (APA):

Lange, B., Larsen, S. E., Højstrup, J., \& Barthelmie, R. J. (2004). Importance of thermal effects and sea surface roughness for offshore wind resource assessment. Journal of Wind Engineering \& Industrial Aerodynamics, 92(11), 959-988. https://doi.org/10.1016/j.jweia.2004.05.005

\section{General rights}

Copyright and moral rights for the publications made accessible in the public portal are retained by the authors and/or other copyright owners and it is a condition of accessing publications that users recognise and abide by the legal requirements associated with these rights.

- Users may download and print one copy of any publication from the public portal for the purpose of private study or research.

- You may not further distribute the material or use it for any profit-making activity or commercial gain

- You may freely distribute the URL identifying the publication in the public portal 


\title{
Importance of thermal effects and sea surface roughness for offshore wind resource assessment
}

\author{
by \\ Bernhard Lange \\ University of Oldenburg, Oldenburg, Germany \\ Søren Larsen, \\ Jørgen Højstrup \\ Rebecca Barthelmie \\ Risø National Laboratory, Roskilde, Denmark
}

Date received:

Corresponding author address:

Bernhard Lange

University of Oldenburg

Department of Physics

ForWind - Center for Wind Energy Research

D-26111 Oldenburg

Germany

Phone: +49-441-36116-733

Fax: +49-441-36116-739

e-mail: Bernhard.Lange@uni-oldenburg.de 


\section{Abstract}

The economic feasibility of offshore wind power utilisation depends on the favourable wind conditions offshore as compared to sites on land. The higher wind speeds have to compensate the additional cost of offshore developments. However, not only the mean wind speed is different, but the whole flow regime, as can e.g. be seen in the vertical wind speed profile. The commonly used models to describe this profile have been developed mainly for land sites. Their applicability for wind power prediction at offshore sites is investigated using data from the measurement program Rødsand, located in the Danish Baltic Sea.

Monin-Obukhov theory is often used for the description of the wind speed profile. From a given wind speed at one height, the profile is predicted using two parameters, Obukhov length and sea surface roughness. Different methods to estimate these parameters are discussed and compared. Significant deviations to Monin-Obukhov theory are found for near-neutral and stable conditions when warmer air is advected from land with a fetch of more than $30 \mathrm{~km}$. The measured wind shear is larger than predicted.

As a test application, the wind speed measured at $10 \mathrm{~m}$ height is extrapolated to $50 \mathrm{~m}$ height and the power production of a wind turbine at this height is predicted with the different models. The predicted wind speed is compared to the measured one and the predicted power output to the one using the measured wind speed. To be able to quantify the importance of the deviations from Monin-Obukhov theory, a simple correction method to account for this effect has been developed and is tested in the same way. 
The models for the estimation of the sea surface roughness were found to lead only to small differences. For the purpose of wind resource assessment even the assumption of a constant roughness was found to be sufficient. The different methods used to derive the Obukhov length $\mathrm{L}$ were found to differ significantly for near-neutral and stable atmospheric stratification. Here again the simplest method using only bulk measurements was found to be sufficient.

For situations with near-neutral and stable atmospheric stratification and long (>30 $\mathrm{km}$ ) fetch, the wind speed increase with height is larger than what is predicted from Monin-Obukhov theory for all methods to estimate $\mathrm{L}$ and $\mathrm{z}_{0}$. It is also found that this deviation occurs at wind speeds important for wind power utilisation, mainly at 5-9 $\mathrm{ms}^{-1}$.

The power output estimation has also been compared with the method of the resource estimation program WAsP. For the Rødsand data set the prediction error of WAsP is about $4 \%$. For the extrapolation with Monin-Obukhov theory with different $\mathrm{L}$ and $\mathrm{z}_{0}$ estimations it is $5-9 \%$. The simple wind profile correction method, which has been developed, leads to a clear improvement of the wind speed and power output predictions. When the correction is applied, the error reduces to $2-5 \%$.

Key Words: Off-Shore, Meteorology, Boundary-Layer, Power Production Estimation, Wind Resource Assessment

\section{Introduction}

It is expected that an important part of the future expansion of wind energy utilisation at least in Europe will come from offshore sites. The first large offshore wind farms are currently being built in several countries in Europe. The economic viability of such projects depends on the favourable wind conditions of offshore sites, since the 
higher energy yield has to compensate for the additional installation and maintenance costs. A reliable prediction of the wind resource is therefore crucial. This requires the modelling of the vertical structure of the surface layer flow, especially the vertical wind speed profile. This is needed, e.g., to be able to extrapolate wind speed measurements performed at lower heights to the planned hub height of a turbine. Also, for turbine design the wind shear is an important design parameter, especially for the large rotor diameters planned for offshore sites.

The wind speed profile in the atmospheric surface layer is commonly described by Monin-Obukhov theory. In homogenous and stationary flow conditions, it predicts a log-linear profile:

$$
u(z)=\frac{u_{*}}{\kappa}\left[\ln \left(\frac{z}{z_{0}}\right)-\Psi_{m}\left(\frac{z}{L}\right)\right]
$$

The wind speed $\mathrm{u}$ at height $\mathrm{z}$ is determined by friction velocity $\mathrm{u} *$, aerodynamic roughness length $z_{0}$ and Obukhov length $L . \kappa$ denotes the von Karman constant (taken as 0.4$)$ and $\Psi_{\mathrm{m}}$ is an universal stability function. Thus, if the wind speed is known at one height, the friction velocity can be derived from eq. (1) and the vertical wind speed profile is determined by two parameters: the surface roughness $z_{0}$ and the Obukhov length L. This relation has originally been developed from the Kansas experiment with measurement height of up to $32 \mathrm{~m}$ [1]. It cannot in general be expected to be valid for the hub heights of today's large wind turbines of 80 to $100 \mathrm{~m}$ or even for the wind shear across the rotor with tip heights of up to $150 \mathrm{~m}$.

The surface roughness of the sea is low compared to land surfaces. This is the main reason for the high wind speeds offshore. However, the roughness is not constant with wind speed as it is for land surfaces. Instead, it depends on the wave field present, 
which in turn depends on wind speed, upstream fetch (distance to coast), water depth, etc. Different models have been proposed to describe these dependencies. Most commonly used is the Charnock model [2], which only depends on friction velocity. Numerous attempts have been made to improve this description by including more information about the wave field, e.g. by including wave age [3] or wave steepness [4] as additional parameters. These additional parameters require wave measurements, which are often not available for wind power applications. A fetch dependent model has therefore been developed, where the wave age has been replaced by utilising an empirical relation between wave age and fetch [5].

The Obukhov length $\mathrm{L}$ has to be derived from measurements at the site. Different methods are available using different kinds of input data: The calculation of $\mathrm{L}$ with the eddy-correlation method requires fast response measurements, e.g. by an ultrasonic anemometer. Wind speed and temperature gradient measurements at different heights can be used to derive L via the Richardson number [6]. The method with the least experimental effort employs a wind speed measurement at one height, water and air temperatures to calculate the bulk Richardson number, which is then related to $\mathrm{L}[7]$.

Monin-Obukhov theory, although developed from measurements over land, has been found to be generally applicable over the open sea [8]. This has been questioned for sites where the flow is influenced by the proximity of land. [9] and [10] showed that the land-sea discontinuity influences the flow for distances of up to 100-200 kilometres. Offshore wind power plants will therefore always be subject to such influences.

In coastal waters, when wind is blowing from land over the sea, the coastline constitutes a pronounced change in roughness and heat transfer. These changes pose a 
strong inhomogeneity to the flow, which may limit the applicability of MoninObukhov theory. Stimulated by measurements of large wind stress over Lake Ontario, Csanady described the processes governing the flow regime under the condition of warm air advection over colder water [11]. He developed an equilibrium theory of a well-mixed layer with a capping inversion for this condition.

Monin-Obukhov theory is a key part of the European Wind Atlas method [12] and the wind resource estimation program WAsP [13], which is most commonly used for offshore wind potential studies (see e.g. [14]) and wind resource estimations from measurements (see e.g. [15]). Also other approaches, like the methodology used in the POWER project [16] are based on this theory.

Also mesoscale flow modelling is used for wind power studies. A comparison of the mesoscale model MIUU [17] and the WAsP program shows differences of up to $15 \%$ in mean wind speed [18]. However, such models are too computationally demanding to be used in wind power applications and a simpler model is needed to be able to estimate these effects.

A validation study with three offshore masts in Denmark revealed differences between measurements and WAsP model results, which correlated with fetch [19]. A combination of the simplified assumptions used in WAsP was believed to be responsible for the deviations.

In this study the impact of different methods and models for the extrapolation of wind speed measurements on the prediction of the wind turbine power production is reinvestigated with data from the Rødsand measurement program in the Danish Baltic Sea, about $10 \mathrm{~km}$ off the coast. A simple ad hoc correction to the Monin-Obukhov wind speed profile is developed with the aim to investigate the importance of 
deviations from the Monin-Obukhov profile on wind resource estimations. The deviations occur when warm air is flowing from land over a colder sea, creating an inhomogeneous wind flow.

Measured wind speeds at $10 \mathrm{~m}$ height are extrapolated to $50 \mathrm{~m}$ height with MoninObukhov theory with different methods to derive $\mathrm{L}$ and different models for the sea surface roughness. This has been repeated including the simple wind profile correction for inhomogeneous wind flow. The results are compared with the measured wind speed at $50 \mathrm{~m}$ height. By converting the wind speeds to power output of an example turbine, the impact of the deviations in wind speed on the estimation of the power production is investigated.

The Rødsand measurement program is briefly introduced in the following section. In section 3, Monin-Obukhov theory is used to predict the wind speed profile with different methods for the derivation of $\mathrm{L}$ and models for estimating $\mathrm{z}_{0}$. The simple correction of the Monin-Obukhov profile for inhomogeneous wind flow in the coastal zone is developed in section 4. In section 5, the impact of the different methods, models and the correction on the estimation of the power production of a wind turbine is investigated. Their impact on the prediction of the wind shear is shown in section 6 . Then conclusions are drawn in the final section.

\section{The Rødsand field measurement program}

The field measurement program Rødsand has been established in 1996 as part of a Danish study of wind conditions for proposed offshore wind farms. A detailed description of the measurement, instrumentation, and data can be found in [20] and [21]. 
The $50 \mathrm{~m}$ high meteorological mast is situated about $11 \mathrm{~km}$ south of the island Lolland in Denmark $\left(11.74596^{\circ} \mathrm{E}, 54.54075^{\circ} \mathrm{N}\right)$ (see Figure 1). The instrumentation of the measurement mast is listed in Table 1. It is located in 7.7 m mean water depth with an upstream fetch (distance to coast) of 30 to more than $100 \mathrm{~km}$ with wind directions from SE to WNW $\left(120^{\circ} \mathrm{N}\right.$ to $\left.290^{\circ} \mathrm{N}\right)$. In the $\mathrm{NW}$ to $\mathrm{N}$ sector $\left(300^{\circ} \mathrm{N}\right.$ to $350^{\circ} \mathrm{N}$ ) the fetch is 10 to $20 \mathrm{~km}$.

All wind speed data are corrected for flow distortion errors due to the mast and the booms with a method developed by Højstrup [23]. Records from situations of direct mast shade have been omitted. Friction velocity is calculated from the data of the ultrasonic anemometer with the eddy-correlation method. Simple correction procedures have been applied to account for the small decrease of the fluxes with height [21].

The air temperature over land in the upwind direction from Rødsand has been estimated from measurements at synoptic stations of the German Weather Service (DWD) and the measurement station Tystofte, located in Denmark (operated by the Risø National Laboratory) (see Table 2 and Figure 1). A more detailed description can be found in [21] and [22].

Not all instruments are available for long term measurements at Rødsand. Therefore, two data sets are used:

- A data set with shorter measurement period, in which ultrasonic and wave measurements are also available. This data set consists of about 4200 half-hourly records. This data set is used for all analyses except in sections 5.2 and 6 . 
- A data set of two years measurement time (5/99 to 5/01), but without sonic and wave measurements, is used in section 5.2. This data set consists of 64000 records of 10-minute averages (61\% availability).

The data have only been selected for the availability of all measurements. For the purpose of wind resource estimations all available data have to be used. Therefore the data have not been selected for stationarity, although Monin-Obukhov theory is only valid for stationary flow conditions. An analysis with data selected for the applicability of the theory can be found in Lange et al. [21].

\section{Extrapolation with Monin-Obukhov theory}

\subsection{Derivation of Obukhov length}

Atmospheric stability is described in Monin-Obukhov theory with the Obukhov length scale $\mathrm{L}$ as stability parameter. Three different ways to derive this parameter are considered:

\section{$\underline{\text { Sonic method }}$}

$\mathrm{L}$ is determined directly from sonic anemometer measurements of friction velocity and heat flux by:

$$
L_{\text {sonic }}=-\frac{u_{*_{s}}{ }^{3}}{\kappa \frac{g}{\bar{T}} \overline{w^{\prime} T^{\prime}}{ }_{s}}
$$

Here $\overline{w^{\top} T}{ }_{s}$ is the covariance of temperature and vertical wind speed fluctuation at the surface, $\mathrm{u}_{*}$ s the surface friction velocity, $\mathrm{T}$ the reference temperature, $\mathrm{g}$ the gravitational acceleration and $\kappa$ the von Karman constant (taken as $\kappa=0.4)$. 
The sonic anemometer measures the sound virtual temperature, which differs from the virtual temperature by $0.1 \bar{T} \overline{w^{\prime} q},[24]$ :

$$
\overline{w^{\prime} T_{\text {sonic }}^{\prime}}=\overline{w^{\prime} T^{\prime}}+0.51 \bar{T} \overline{w^{\prime} q^{\prime}}=\overline{w^{\prime} \Theta_{v}^{\prime}}-0.1 \bar{T} \overline{w^{\prime} q^{\prime}}=\overline{w^{\prime} \Theta_{v}^{\prime}}-0.1 \bar{T} u_{*} q_{*}
$$

Here $q$ is the absolute humidity and $\Theta_{v}$ the virtual potential temperature. No humidity measurement is available at Rødsand. Therefore only an average humidity flux could be accounted for in the calculation of the stability parameters. Following Geernaert and Larsen [25], a relative humidity of $100 \%$ and $70 \%$ has been assumed at the surface and at $10 \mathrm{~m}$ height, respectively. The measured water temperature has been used to transform these to absolute humidity. The humidity scale $\mathrm{q} *$ and the vertical humidity profile have been calculated with a diabatic profile with standard humidity stability functions and a humidity roughness length of $\mathrm{z}_{0 \mathrm{q}}=2 \cdot 1 \cdot 10^{-4} \mathrm{~m}[25]$.

\section{Gradient method}

Temperature and wind speed difference measurements at $10 \mathrm{~m}$ and $50 \mathrm{~m}$ height are used to estimate the gradient Richardson number $\mathrm{Ri}_{\Delta}$ :

$$
R i_{\Delta}\left(z^{\prime}\right)=\frac{\frac{g}{\bar{T}}\left(\frac{\Delta \overline{T_{v}}}{\Delta z}+\frac{g}{C_{p}}\right)}{\left(\frac{\Delta \bar{u}}{\Delta z}\right)^{2}}
$$

Here $\Delta \mathrm{T}_{\mathrm{v}} / \Delta \mathrm{z}$ is the virtual temperature difference $\Delta \mathrm{T}_{\mathrm{v}}$ at a vertical height difference $\Delta \mathrm{z}$. Equally, $\Delta \mathrm{u} / \Delta \mathrm{z}$ is the wind speed difference $\Delta \mathrm{u}$ at the vertical height difference $\Delta \mathrm{z} . \mathrm{C}_{\mathrm{p}}$ is the specific heat of air at constant pressure. Humidity at the two heights has been estimated as described above. The height $z^{\prime}$ at which this Ri number is valid can be estimated as $\mathrm{z}^{\prime}=\left(\mathrm{z}_{1}-\mathrm{Z}_{2}\right) / \ln \left(\mathrm{z}_{1} / \mathrm{z}_{2}\right)$ [26]. The gradient Richardson number is converted to L by means of the following relation based on the Kansas results [1], [27]: 


$$
L_{\text {Gradient }}=\left\{\begin{array}{cc}
\left(\frac{z^{\prime}}{R i}\right) & R i<0 \\
\frac{z^{\prime}(1-5 R i)}{R i} & 0<R i<0.2
\end{array}\right.
$$

\section{$\underline{\text { Bulk method }}$}

Air and sea temperature measurements are used together with the wind speed at $10 \mathrm{~m}$ height. An approximation method proposed by Grachev and Fairall [7] has been used. In the calculation of the virtual temperatures, humidity has been accounted for with the assumptions stated above.

For the bulk method the sea surface temperature is required. This is not measured at Rødsand and therefore had to be replaced by the water temperature measured at a depth of about $2 \mathrm{~m}$. Due to the cool skin effect this temperature is on average slightly higher than the skin temperature [28]. This leads to a small but systematic overprediction of the temperature difference between the surface and $10 \mathrm{~m}$ height and consequently to an overprediction of the stability parameter $|10 \mathrm{~m} / \mathrm{L}|$, i.e. the calculated values of $10 \mathrm{~m} / \mathrm{L}$ are slightly too high for stable and too low for unstable conditions.

\subsection{Sea surface roughness}

Compared to land surfaces the surface roughness of water is very low. Additionally, it is not constant, but depends on the wave field, which in turn is determined by the wind speed, distance to coast (fetch), etc. It is investigated how different models to describe the sea surface roughness influence the prediction of the wind profile (eq. (1)). Four models for sea surface roughness $\mathrm{z}_{0}$ are considered:

\section{Constant roughness}


The assumption of a constant sea surface roughness is often used in applications because of its simplicity, e.g. in the wind resource estimation program WAsP [13]. A value of $\mathrm{z}_{0}=0.2 \mathrm{~mm}$ is assumed.

\section{$\underline{\text { Charnock relation }}$}

The most common model taking into account the wave field by its dependence on friction velocity $\mathrm{u}_{*}$ is the Charnock relation [2]:

$$
z_{0}=z_{c h} \frac{u_{*}^{2}}{g}
$$

Here $\mathrm{g}$ is the gravitational acceleration and $\mathrm{z}_{\mathrm{ch}}$ the empirical Charnock parameter. The standard value of $\mathrm{z}_{\mathrm{ch}}=0.0185$ has been used [29].

\section{Wave age model}

The Charnock relation works well for the open ocean, but for coastal areas it was found that the Charnock parameter is site specific, due to the influence of other physical variables like fetch on the wave field. Numerous attempts have been made to find an empirical relation for the sea surface roughness with an improved description of the wave field. No consensus on the most suitable scaling groups has emerged yet. Different relations have been tested with the Rødsand data [5] and an extension of the Charnock relation by a parameterisation of the Charnock parameter with wave age as additional parameter by Johnson et al. [3] is used:

$$
z_{c h}=A\left(\frac{c_{p}}{u_{*}}\right)^{B}
$$

Here $c_{p} / u *$ is the wave age, the ratio of the velocity of the peak wave component $c_{p}$ and the friction velocity $\mathrm{u} *$. The values for the empirical constants A and B are taken as $\mathrm{A}=1.89$ and $\mathrm{B}=-1.59[3]$. 


\section{Fetch model}

The wave age model requires measurements of the peak wave velocity, which are often not available for wind power applications. A fetch dependent model has therefore been developed, where the wave age has been replaced by utilising an empirical relation between wave age and fetch.

Kahma and Calkoen [30] found the following empirical relation between the dimensionless peak frequency and the dimensionless fetch:

$$
\frac{u_{*}}{g} \omega_{p}=C\left(\frac{g}{u_{*}{ }^{2}} x\right)^{D}
$$

Here $\omega_{\mathrm{p}}$ is the peak wave frequency and $\mathrm{x}$ the fetch in metres. Values of $\mathrm{C}=3.08$ and $\mathrm{D}=-0.27$ have been used for the coefficients [30].

The influence of fetch on wave parameters has been determined by field experiments with winds blowing approximately perpendicular to a straight coastline. To use these relations for any coastline, an effective fetch $\mathrm{x}_{\mathrm{eff}}$ for a particular wind direction $\phi$ is defined as the integral over the fetch $\mathrm{x}(\alpha)$ for directions from $\alpha=\phi-90^{\circ}$ to $\alpha=\phi+90^{\circ}$, weighted by a cosine squared term, normalised, and divided by the fetch which would result from a straight coastline.

$x_{e f f}(\phi)=\frac{2 \int_{-\pi / 2}^{\pi / 2} x(\phi-\varphi) \cos ^{2}(\phi-\varphi) d \varphi}{4 / \pi}$

With the assumption of deep water conditions the left hand side of eq. (8) can be identified as the inverse wave age $\mathrm{u} * / \mathrm{c}_{\mathrm{p}}$ using the dispersion relation. This relation can then be used to eliminate the wave age from eq. (7):

$$
z_{c h}=A C^{B}\left(\frac{g}{u_{*}^{2}} x_{e f f}\right)^{B D}
$$




\subsection{Comparison of predicted and measured wind speed profiles}

The wind speed ratio between $10 \mathrm{~m}$ and $50 \mathrm{~m}$ height is predicted using MoninObukhov theory. From the diabatic wind profile (see eq.(1)) the wind speed ratio is calculated as:

$$
\frac{u\left(z_{2}\right)}{u\left(z_{1}\right)}=\frac{\left[\ln \left(\frac{z_{2}}{z_{0}}\right)-\Psi_{m}\left(\frac{z_{2}}{L}\right)\right]}{\left[\ln \left(\frac{z_{1}}{z_{0}}\right)-\Psi_{m}\left(\frac{z_{1}}{L}\right)\right]}
$$

Here $z_{0}$ is the aerodynamic roughness length and $\Psi_{m}(\mathrm{z} / \mathrm{L})$ the integrated stability function, for which the Businger-Dyer formulation [1] is used. For the empirical parameters $\beta$ and $\gamma$ the values of the Kansas measurement reanalysed by [27] for a von Karman constant of 0.4 are used $(\beta=4.8$ and $\gamma=19.3)$.

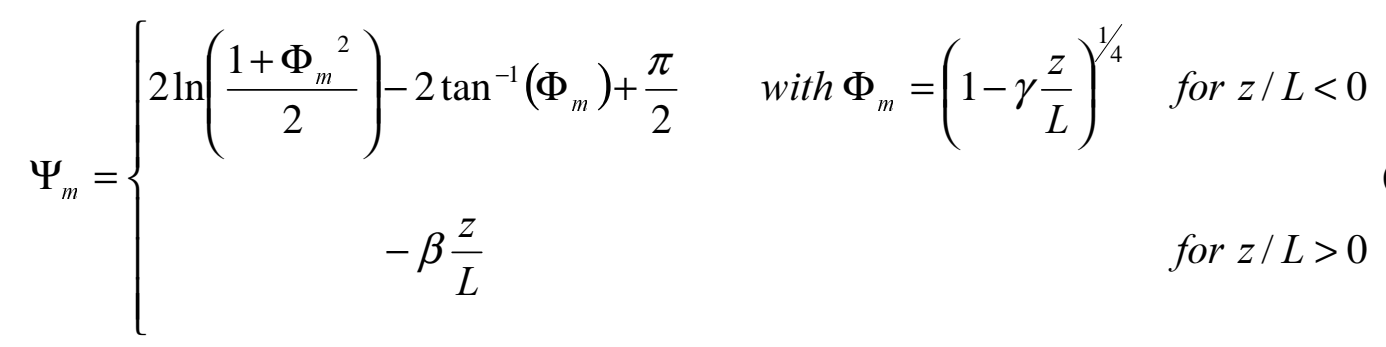

A deviation $\mathrm{R}$ is defined as the ratio between measured and predicted wind speeds at $50 \mathrm{~m}$ height, where the prediction is made from the measured wind speed at $10 \mathrm{~m}$ height with eq. (11):

$$
R=\frac{u(50)}{u(10)} \frac{\left[\ln \left(\frac{10}{z_{0}}\right)-\Psi_{m}\left(\frac{10}{L}\right)\right]}{\left[\ln \left(\frac{50}{z_{0}}\right)-\Psi_{m}\left(\frac{50}{L}\right)\right]}
$$


This deviation $\mathrm{R}$ has been computed for the Rødsand data for all combinations of the three models to derive the Obukhov length $\mathrm{L}$ and the four models of the sea surface roughness.

Systematic deviations are found in all cases for data with stable stratification. As example, the deviations $\mathrm{R}$ for the gradient method to derive $\mathrm{L}$ are shown in Figure 2, using the Charnock relation to model the sea surface roughness. A good agreement is found in the unstable region $(10 \mathrm{~m} / \mathrm{L}<-0.05)$. For stable conditions the wind speed at $50 \mathrm{~m}$ height is systematically higher than predicted by Monin-Obukhov theory. The deviation increases with increasing stability parameter $10 \mathrm{~m} / \mathrm{L}$.

The large scatter, which is visible in Figure 2, is due to the fact that the data have not been selected for stationary flow conditions. Data from periods with large changes in the atmospheric flow lead to large scatter. From [21] it can be seen that the scatter is considerably reduced if records with larger nonstationarity of wind speed, wind direction, temperatures etc. are excluded from the analysis.

For comparison of the different methods, the bin-averaged deviations $\mathrm{R}$ for the three different methods to derive $\mathrm{L}$ are shown in Figure 3 together with their standard errors. Only bins with more than 20 records have been used. It can be seen that for all methods the agreement is good for unstable stratification. For near-neutral and stable stratification the wind speed prediction at $50 \mathrm{~m}$ height is too low by all methods. The deviations increase with increasing stability parameter $10 \mathrm{~m} / \mathrm{L}$ for all methods, with the exception of the sonic method for stable conditions. Deviations are between $-3 \%$ and $3 \%$ for unstable conditions and between $3 \%$ and $18 \%$ for stable conditions.

The difference in the magnitude of the deviations can be understood from the way the Obukhov length is calculated using the different methods. In the determination of $\mathrm{L}$ 
with the gradient method the applicability of Monin-Obukhov theory has been assumed (eq. (5)). This means that the predicted wind speed ratio between $10 \mathrm{~m}$ and $50 \mathrm{~m}$ height is already included in the calculation of L. From eq. (4), (5) and (12) it can be seen that the diabatic term in the vertical wind profile is inversely proportional to the wind speed height ratio squared $\left(\Psi_{\mathrm{m}}(\mathrm{z} / \mathrm{L}) \sim 1 / \Delta \mathrm{u}^{2}\right)$ for stable stratification. Therefore, any deviation between measured and predicted profile is amplified with this method.

The small magnitude of the deviation in the bulk method is due to the fact that only absolute quantities are used instead of differences. Contrary to the gradient method, a deviation of the measured from the predicted profile will therefore only lead to a small relative difference in the calculation of L. Additionally, the systematic error caused by using the bulk water temperature instead of the sea surface temperature leads to a small over-prediction of $10 \mathrm{~m} / \mathrm{L}$ on the stable side. This partly compensates for the deviations between measured and predicted wind speed profile.

To investigate if the deviations $\mathrm{R}$ can be caused by inappropriate modelling of the sea surface roughness, the four different roughness models are compared in Figure 4. The bin-averaged deviations $\mathrm{R}$ are plotted versus the stability parameter $10 \mathrm{~m} / \mathrm{L}$. The bulk method has been used to derive L. It can be seen that the choice of model for the sea surface roughness does not have a large impact on the dependence of the deviations on the stability parameter z/L. Thus, they cannot be responsible for the deviations found.

Sea surface roughness mainly depends on wind speed (or friction velocity, which are related). Figure 5 shows the dependency of the bin-averaged deviation on wind speed at $10 \mathrm{~m}$ height for the four roughness models. The data are selected for unstable $(\mathrm{L}<0)$ and stable $(\mathrm{L}>0)$ stratification. For unstable stratification the deviations are small 
$(<4 \%)$, while for stable data deviations of up to $25 \%$ are found. The constant roughness assumption leads to the smallest deviations up to a wind speed of about 8 $\mathrm{ms}^{-1}$, but to the largest deviations for higher wind speeds. From the other models, the Charnock relation always shows the smallest deviation. The wave age and fetch models show only little difference and slightly larger deviations than the Charnock model.

\section{Correction of the Monin-Obukhov wind speed profile for coastal influence}

\subsection{Description of the flow regime}

The measurement station Rødsand is surrounded by land in distances between 10 and $100 \mathrm{~km}$ and thus the air in the boundary layer will always be advected from land. Due to the large differences in heat capacity and conduction between land and water the air over land will often be warmer than the sea surface temperature. Warm air is advected over the colder sea to the measurement station especially at daytime, when the land is heated by the sun, and in early spring, when the water temperature is still low from winter. Large temperature differences between the advected air and the sea surface can occur. At Rødsand, temperature differences of up to $9^{\circ} \mathrm{C}$ were measured.

The flow regime that develops in this situation has been described by several authors. We follow the explanation given by Csanady [11] and Smedman et al. [31]: When warm air is blown over the cold sea, a stable stratification develops immediately as the air adjacent to the sea surface will be cooled. Simultaneously, an internal boundary layer develops at the shoreline due to the roughness and heat flux changes. In the case when warm air advects over a cold sea, a stable internal boundary layer (SIBL) emerges, characterised by low turbulence and therefore small fluxes and slow 
growth (see Figure 6 (a)). The warm air is cooled from below while the sea surface temperature will remain almost constant in this process due to the large heat capacity of water. Eventually, the air close to the sea surface will have the same temperature as the water and the atmospheric stability will be close to neutral at low heights. Above the internal boundary layer the air still has the temperature of the air over land and near the top of the SIBL an inversion lid has developed with strongly stable stratification separating these two regions (see Figure 6 (b)). Thus, while the stability in the mixed layer is close to neutral, the elevated stable layer influences the wind speed profile and leads to a larger wind speed gradient than expected for an ordinary near neutral condition.

Due to the small fluxes through the inversion lid, this flow regime is in a quasiequilibrium state and can survive for large distances before the heat flow through the inversion eventually evens out the difference in potential temperatures. It can be expected that eventually the neutral boundary layer is recovered, which is known from open ocean observations [8].

\subsection{Prediction of the inversion height}

A theory for a mixed layer flow with capping inversion has been developed by

Csanady [11]. The so-called buoyancy parameter $\mathrm{Bu}$ is proposed to predict if such a flow regime will develop. He found that an inversion lid is likely to develop if $\mathrm{Bu}>30$. $\mathrm{Bu}$ is estimated from:

$$
B u=\frac{b}{f v_{g}}=g \frac{\Delta \rho}{\rho} \frac{1}{f v_{g}}
$$


Here $g$ is the gravitational acceleration, $b$ is the buoyant acceleration $(b=g \Delta \rho / \rho), \rho$ the air density, $\Delta \rho$ the air density difference between surface and geostrophic level at constant pressure, $\mathrm{f}$ the Coriolis parameter and $\mathrm{v}_{\mathrm{g}}$ the geostrophic wind speed.

For the Rødsand measurement, the geostrophic wind speed and the air density at geostrophic level have been estimated from the measured data at the Rødsand mast and at the surrounding land stations. It has been assumed that the air at this height is advected from land without temperature change and that the temperature stratification over land is neutral (see [21]).

The buoyancy parameter $\mathrm{Bu}$ aims to determine if a mixed layer with inversion lid can develop in a certain situation. The influence of a flow regime with mixed layer and capping inversion on the wind speed profile can be expected to depend on the height of the inversion. If the inversion is very high it will probably have little influence on the wind speed profile up to $50 \mathrm{~m}$ height, while a low inversion height can be expected to have a large impact. Csanady proposes the following expression for the depth of the mixed layer $h$ in equilibrium conditions [11]:

$$
h=A \frac{1}{g} \frac{\rho}{\Delta \rho} u_{*}^{2}
$$

He estimates the empirical parameter A to 500. The inversion height estimated from airborne measurements over the Baltic Sea has been found to agree reasonably well with eq. (15) [32].

The bin averaged deviation $\mathrm{R}$ for situations with long fetch $(>30 \mathrm{~km})$ is shown versus the inversion height $\mathrm{h}$ in Figure 7 (in logarithmic scale). A correlation can be seen with large ratios for low inversion heights of below $100 \mathrm{~m}$, decreasing rapidly with increasing inversion height and reaching a constant level at an inversion height of 
about $1000 \mathrm{~m}$. This is in accord with the picture that an inversion height in the order of the boundary layer height will not lead to changes in the profile.

It has to be kept in mind that the estimated inversion height $\mathrm{h}$ is for equilibrium conditions only, i.e. when the mixed layer and capping inversion already are developed. Therefore the theory cannot be used for small fetches. The correlation between $\mathrm{h}$ and $\mathrm{R}$ has been found to hold for fetches larger than $30 \mathrm{~km}$ [21].

\subsection{Development of a simple correction method}

The deviations due to thermal effects in coastal waters will lead to errors in wind resource prediction made with Monin-Obukhov theory. If e.g. the mean wind speed at hub height is estimated from measurements at a lower height, the wind resource will be estimated too low.

A micrometeorological model to take into account these effects is not available. Therefore a simple correction method is developed here to investigate the importance of this effect for wind resource estimations. In Figure 7 it is shown that the deviation decreases with increasing height of the inversion layer. It is assumed that the deviation increases linearly with height. The simplest correction method is therefore to add a linear correction term to the wind speed profile of the Monin-Obukhov theory (see eq. 1), which is proportional to the measurement height $\mathrm{z}$ and inversely proportional to the estimated inversion height h:

$$
u(z)=\frac{u_{*}}{\kappa}\left[\ln \left(\frac{z}{z_{0}}\right)-\Psi_{m}\left(\frac{z}{L}\right)+c \frac{z}{h}\right]
$$


This correction is used for all records with fetch greater than $30 \mathrm{~km}$ and buoyancy parameter Bu greater than 30. From the Rødsand measurements the correction factor $\mathrm{c}$ is estimated to be about 4 .

The effect of this correction on the deviation $\mathrm{R}$ is shown in Figure 8 to Figure 9. In Figure $8 \mathrm{R}$ is bin averaged with respect to the stability parameter $10 \mathrm{~m} / \mathrm{L}$ for different methods to derive L. This can be compared to Figure 3, where the same is shown without correction. It can be seen that the deviations on the stable side are reduced considerably for all three methods. Especially for the gradient method the deviation is greatly reduced since with this method the proposed wind speed profile with correction for thermal influences is used twice: in the calculation of $\mathrm{L}$ and in the prediction of the $50 \mathrm{~m}$ wind speed. For the sonic method also the deviation in the unstable regime decreases. This is due to the fact that some records with large deviations and $\mathrm{Bu}>30$ are erroneously regarded as unstable by the sonic method, probably due to the large measurement uncertainty and sampling variability of the friction velocity.

Figure 9 shows the deviation $\mathrm{R}$ versus wind speed as in Figure 5, but with the proposed wind profile correction. It can be seen that the reduction of the deviation is largest for small wind speeds. This is due to the fact that the inversion height after Csanady is proportional to the friction velocity squared (see eq. (15)). Since the correction is inversely proportional to $h$, it decreases with increasing wind speed. However, comparing Figure 9 with Figure 5 it should be noted that the correction is effective for wind speeds up to $12 \mathrm{~ms}^{-1}$. 


\section{Predictions of power production}

So far, different methods to derive the stability parameter L, different models for the sea surface roughness and a simple wind profile correction for the influence of a thermally modified flow regime have been discussed. In the context of wind energy utilisation it is important to know, which impact these different approaches have for the prediction of the power output of an offshore wind turbine. It is not only important how large an effect like e.g. the fetch dependence of the sea surface roughness is, but also how frequently it occurs and at which wind speed.

This is investigated in an example application: the power production of an example wind turbine with hub height $50 \mathrm{~m}$ and $1 \mathrm{MW}$ rated power output (see Figure 10 for the power curve) is estimated from the wind speed measurement at $10 \mathrm{~m}$ height using the different methods and models described in the previous sections. The estimated production is then compared with that obtained by using the measured wind speed at $50 \mathrm{~m}$ height. The background for this example is that often wind speed measurements are made at meteorological masts, which are lower than the hub height of the proposed turbines. These need to be extrapolated to hub height for the prediction of the power production.

\subsection{Comparison of different methods}

The measured wind speed at $10 \mathrm{~m}$ height is extrapolated to hub height and converted to power output with the power curve of the example turbine. For the extrapolation to hub height different methods are used for:

- derivation of the Obukhov length L: Sonic method, gradient method and bulk method (see section 3.1) 
- modelling the sea surface roughness $\mathrm{z}_{0}$ : constant roughness, Charnock relation, wave age model, fetch model (see section 3.2)

- simple wind profile correction for deviations from Monin-Obukhov theory for warm air advection from land (see section 4)

The resulting mean of the power output is compared to that derived from the measured wind speed at $50 \mathrm{~m}$ (hub height).

The mean power output for the data set derived from the measured wind speed at hub height $(50 \mathrm{~m})$ is $498 \mathrm{~kW}$. This is compared to the power output estimated from the extrapolation of the wind speed from $10 \mathrm{~m}$ measurement height to hub height. The result is shown in Figure 11, where the power output prediction error, defined as $\left(\mathrm{P}_{\text {pred }}\right.$ $\left.-\mathrm{P}_{\text {meas }}\right) / \mathrm{P}_{\text {meas }}$, is shown for all extrapolation methods.

The estimated production with wind speed extrapolation is lower than that using the measured wind speed at hub height in all cases with errors ranging from $3 \%$ to $9 \%$. Significant differences are found for the performance of the different methods to derive the Obukhov length L: The results for the sonic and bulk methods are almost equal with about 3-6\% and 3-7\% error, respectively, but the results obtained with the gradient method show larger errors of 5-9\%. For the different sea surface roughness methods it can be seen that the constant roughness assumption and the Charnock relation lead to almost equal results. Equally, there is almost no difference between the wave age and the fetch models, which show a slightly (about 1\%) higher error. The correction method for the wind speed profile leads to a significant reduction in the prediction error in all cases. For the sonic and bulk methods the error is reduced by about $2 \%$, while for the gradient method a reduction of about $3 \%$ is obtained. 
The variation of the absolute prediction error with stability can be seen in Figure 12 for the three methods to derive $\mathrm{L}$ with and without applying the correction for flow with inversion layer from section 4 . The difference between predicted and measured power output has been bin averaged with respect to the stability parameter $10 \mathrm{~m} / \mathrm{L}$. Without correction, both the gradient and bulk methods show large errors for stable stratification. This shows that situations with stable stratification are important for the estimation of the power output of an offshore wind turbine, even though the wind speeds are on average smaller than for near-neutral conditions. The simple correction for the flow modification due to the land-sea transition is shown to have an important impact on the absolute power production estimation, since it improves the estimation significantly for stable conditions.

Figure 13 shows the variation of the absolute prediction error with wind speed. The difference between predicted and measured power output has been bin averaged with respect to wind speed bins of $1 \mathrm{~ms}^{-1}$. The four roughness models (see section 3.2) have been used with the bulk method to derive $\mathrm{L}$ with correction. The estimation errors are most important in the wind speed range 5-9 $\mathrm{ms}^{-1}$, while for wind speeds in the range of $9-13 \mathrm{~ms}^{-1}$ both wind speed and power output estimation show only small errors. For very low and very high wind speeds no prediction error occurs, since for lower wind speeds the power production is small and so is the absolute error. For very high wind speeds above $13 \mathrm{~ms}^{-1}$ the decreasing steepness in the power curve reduces the impact of errors in wind speed estimation on power production estimation. 


\subsection{Comparison with results from a longer time series}

The results obtained above are compared with those from a data set of the two years time series where only part of the instruments are available (see section 2). Therefore the sonic method to derive $\mathrm{L}$ and the wave age model for $\mathrm{z}_{0}$ cannot be used.

The results are shown in Figure 14. Compared to the result of the short time series (Figure 11) the overall picture remains unchanged. The mean production derived from the measurement at hub height is slightly smaller. Equally, the prediction errors are slightly smaller, while the comparison of the different methods shows the same overall picture as before. This shows that the effects found are not due to unusual conditions during the measurement period, but are at least qualitatively representative.

\subsection{Comparison with the wind resource estimation program WAsP}

The results are also compared with the mean power production calculated with the wind resource assessment program WAsP in Figure 14. For the WAsP calculations, the same data as for the extrapolation with the different methods have been used, i.e. the wind speed measurements at $10 \mathrm{~m}$ height. The estimated mean production with WAsP is about $4 \%$ lower than that derived from the wind speed measurements at hub height.

When no correction is applied for wind profile correction, the extrapolation methods described above show a higher prediction error then WAsP, even though the atmospheric stability and sea surface roughness are estimated for each record, while the WAsP method uses a mean profile.

The WAsP method assumes a constant sea surface roughness and a wind speed profile corresponding to a slightly stable mean atmospheric stability. This means that the 
mean stability used in WAsP for the site Rødsand leads on average to better results than the actually measured atmospheric stability.

As could also be seen from Figure 11, the prediction error is smaller for the bulk than for the gradient method. This is due to the influence of the flow regime with inversion layer on the profiles, which leads to a larger error in the estimation of L.

For the sea surface roughness modelling there is little difference between the constant roughness assumption, as also used by WAsP, and the use of the Charnock relation. The fetch model for the roughness leads to an increased error.

The prediction accuracy is improved greatly when the simple correction for the wind profile is applied. With this correction, the bulk method to derive $\mathrm{L}$ and the constant roughness assumption, the predicted mean power production error is less than $2 \%$. This shows that a large part of the prediction error found in all methods is due to the modified wind profile stemming from a flow regime of a mixed layer with capping inversion.

\section{Prediction of the wind shear}

Wind shear is the change of wind speed with height in the vertical wind speed profile. It is one of the most important parameters for wind turbine design, since it gives raise to important fatigue loading of the rotor support and especially the blades. The blades of a wind turbine experience an alternating wind force for each rotation depending on their position in the wind profile.

For design calculations, a power law profile as a simplified form of the wind profile is often used to describe the wind speed variation with height [34]:

$$
u(z)=u\left(z_{\text {hub }}\right)\left(\frac{z}{z_{h u b}}\right)^{a}
$$


Thus, the wind speed $\mathrm{u}$ at height $\mathrm{z}$ is only determined by the wind speed at hub height $\mathrm{u}\left(\mathrm{z}_{\mathrm{hub}}\right)$ and the power law exponent a. A value of $\mathrm{a}=0.2$ is recommended in the current version of the IEC certification guidelines [34].

Figure 15 shows a comparison of different forms of the vertical wind speed profile and the resulting wind shear. A wind speed of $10 \mathrm{~ms}^{-1}$ at a hub height of $80 \mathrm{~m}$ has been assumed as example. Shown are the power law profile with an exponent of $\mathrm{a}=0.2$, the logarithmic profile with roughness length $\mathrm{z}_{0}=0.0002 \mathrm{~m}$, the MoninObukhov profile with the same roughness length and Obukhov length $\mathrm{L}=200 \mathrm{~m}$, and the profile with inversion layer correction from eq. (16), which fits the Rødsand measurements, with the same parameters and inversion height $\mathrm{h}=200 \mathrm{~m}$.

It is obvious that, due to the small roughness length, the wind shear of the logarithmic profile is smaller than of the power law profile. The power law and the logarithmic profiles do not account for stability effects. For moderately stable conditions the Monin-Obukhov profile shows a wind shear comparable to that of the power law profile. It was shown in the previous sections that the wind shear at Rødsand is larger than predicted by Monin-Obukhov theory for slightly stable conditions. The profile developed there (eq. (16)) shows a larger wind shear than the power law relation.

To compare the wind shear of the different profiles with the Rødsand measurements, the wind speed ratio between $50 \mathrm{~m}$ and $30 \mathrm{~m}$ height is used. Figure 16 shows how this ratio clearly depends on the atmospheric stability. Power law and logarithmic profiles lead to constant values for this ratio, as they do not take this stability into account. The wind shear predicted by the logarithmic profile with $\mathrm{z}_{0}=0.0002 \mathrm{~m}$ is approximately that measured for neutral stability conditions. The power law profile with $\mathrm{a}=0.2$ leads to a higher wind shear estimate. But even for this the measured wind shear at stable conditions is systematically higher. The Monin-Obukhov profile does 
in general follow the measured dependence of the wind shear on stability, but predicts too small values for stable stratification. This is due to the effect of the warm air advection with inversion layer discussed in section 4 . An example of the result of the ad hoc correction term (eq.(16)) for an inversion layer height of $200 \mathrm{~m}$ is also shown in Figure 16. It can be seen that this effect can qualitatively explain the increased wind shear.

For load calculations it is also important at which wind speeds the cases of high wind shear occur. This can be seen in Figure 17, where the wind speed ratio is shown versus wind speed at $10 \mathrm{~m}$ height. The same data are also shown as bin averages in Figure 18 along with their standard errors and standard deviations. The data have been segregated according to atmospheric stability in unstable $(10 \mathrm{~m} / \mathrm{L}<-0.05)$, near-neutral $(-0.05<10 \mathrm{~m} / \mathrm{L}<0.05)$ and stable $(10 \mathrm{~m} / \mathrm{L}>0.05)$ classes. For wind speeds of up to 13 $\mathrm{ms}^{-1}$ wind speed ratios have been measured which exceed the estimation of the power law profile. These are mainly stably stratified. Compared to land surfaces, in offshore conditions stably stratified flow can occur at higher wind speeds because of the low surface roughness.

It can also be seen in Figure 17 that for high wind speeds the minimum wind shear tends to increase, while the maximum wind shear tends to decrease. Thus, the bin averaged wind shear does not show a clear dependency on wind speed for higher wind speeds (see Figure 18). For lower wind speeds up to $10 \mathrm{~ms}^{-1}$ the wind shear decreases with wind speed for stable and near-neutral conditions.

A strong dependency of the wind shear on atmospheric stability can be seen in Figure 17 and Figure 18: While for unstable conditions the wind shear is even smaller than predicted by the logarithmic wind profile with $\mathrm{z}_{0}=0.0002 \mathrm{~m}$, for stable classification it exceeds the power law profile with $\mathrm{a}=0.2$, which corresponds to $\mathrm{z}_{0}=0.34 \mathrm{~m}$ at $50 \mathrm{~m}$ 
height. For the Rødsand data set the dependency of the wind shear on atmospheric stability seems more important than on wind speed. For the wind speed range available in the data set no clear effect of the sea surface roughness can be found, which would result in an increase of roughness with increasing wind speed. Data at higher wind speeds are necessary to investigate the importance of this effect for extreme wind conditions.

\section{Conclusion}

Models to describe the flow regime in the coastal zone have been compared with data from the Rødsand measurement program in the Danish Baltic Sea. Focus of the investigation has been the description of the vertical wind speed profile for resource assessment and wind shear modelling in offshore wind power utilisation.

The vertical wind profile has been described by Monin-Obukhov theory and different models have been applied for the estimation of the two parameters used in this description: the Obukhov length and the sea surface roughness. For near-neutral and stable stratification large deviations from the measurements have been found in all cases. These are believed to be due to the inhomogeneous flow situation near the landsea discontinuity. To investigate the importance of this effect for wind resource assessment, a simple correction method has been developed for the vertical wind speed profile.

To test the different models, the wind speed at $50 \mathrm{~m}$ height has been extrapolated from the measurement at $10 \mathrm{~m}$ height. To investigate the importance of the differences for wind power output estimations, the extrapolated wind speeds have also been converted to power production estimates. The following options have been used for extrapolation: 
- Three different methods to derive the Obukhov length have been used, which utilise different measured quantities.

- Four sea surface roughness models of different complexity have been tested.

- A simple correction term has been applied in the equation of the vertical wind speed profile to account for the modification of the wind speed profile in a flow regime of a mixed layer capped by an inversion.

The three different methods to derive $\mathrm{L}$ from the measurements were found to disagree for stable atmospheric conditions. This is believed to be a consequence of the flow regime with mixed layer capped by an inversion. Monin-Obukhov theory is not applicable here. The largest differences were found for the method deriving L via the Richardson number from measured profiles of temperature and wind speed. This is explained by the large difference in these profiles in the modified flow from usual Monin-Obukhov theory. Consequently, the simple correction method for the flow regime improved these results most. The derivation of $\mathrm{L}$ from sonic measurements $(\mathrm{u} *$ and w' $\left.\mathrm{T}^{\prime}\right)$ or from bulk measurements $\left(\mathrm{T}_{\text {sea }}, \mathrm{T}_{\text {air }}, \mathrm{U}\right)$ showed less strong deviations.

The difference between the different models for the sea surface roughness is small compared to differences of other model choices. The simplest assumption of a constant roughness was found to be sufficient for the purpose of wind resource assessment. The reason is that errors of this method first become important at high wind speeds, where the power curve of the turbine is flat. Therefore the wind speed prediction errors do not lead to errors in production estimation. Compared to the assumption of constant roughness, the Charnock relation does not lead to improvements in power output prediction. The more complex sea surface roughness models based on wave age dependency were found to actually increase the prediction 
error. The reason might be that the wave age dependency of the Charnock parameter suffers from self-correlation problems [33].

When the usual Monin-Obukhov profile is used, the wind shear in the surface layer is under-estimated at the Rødsand site by all models for $\mathrm{L}$ and $\mathrm{z}_{0}$, when the atmospheric stratification is near-neutral or stable and the fetch is long $(>30 \mathrm{~km})$. In contrast, all models showed reasonable results for unstable stratification.

This effect is believed to be due to the flow regime, which develops when warmer air is blown from land over a colder sea. At some distance behind the coastline a flow regime develops, which consists of a mixed layer at the surface, capped by an inversion layer. In such a flow regime Monin-Obukhov theory is no longer applicable.

A simple correction term has been applied in the equation of the vertical wind speed profile (see eq. (1)):

$u(z)=\frac{u_{*}}{\kappa}\left[\ln \left(\frac{z}{z_{0}}\right)-\Psi_{m}\left(\frac{z}{L}\right)+c \frac{z}{h}\right]$

Here $\mathrm{h}$ is the height of the inversion and $\mathrm{c}$ is an empirical constant, estimated to $\mathrm{c}=4$ by a fit to the Rødsand data.

The predictions of the wind speed profile have been repeated with the different models for sea surface roughness and Obukhov length. For the Rødsand data it is found that this simple correction leads to a clear improvement of the predictions for stable conditions. It has also been shown that this effect occurs predominantly at wind speeds of 5 to $9 \mathrm{~ms}^{-1}$, which are important for power production with wind turbines. More than half of the error in the prediction of the mean power output of an example turbine was due to this effect. 
The mean power output estimation made by extrapolation of the wind speed measurements from $10 \mathrm{~m}$ to $50 \mathrm{~m}$ height with the different methods was also compared with the standard WAsP method. The WAsP extrapolation yielded a $4 \%$ too low mean power output. This was slightly less than for the best methods using MoninObukhov theory. It shows that the assumption of a mean atmospheric stability performed even better than Monin-Obukhov theory, which uses the actually measured time series of stability conditions. The flow modification at the coastline leading to a mixed layer flow with capping inversion is believed to be the main cause of the prediction error. The error was reduced to only $2 \%$ when the proposed simple correction was applied.

From these findings it is concluded that the wind resource estimation at offshore sites is more complex than usually believed. Not only the variable sea surface roughness, the determination of the atmospheric stability and the growth of the internal boundary layer complicate the situation, but also the land-sea discontinuity can lead to a special flow situation far offshore. In this flow regime the wind speed increases more rapidly with height than predicted by Monin-Obukhov theory. It should be noted that these deviations, although caused by the coastal discontinuity, where found far offshore for fetches of 30 to $100 \mathrm{~km}$.

The wind shear resulting from different forms of the vertical wind speed profile has been investigated by a comparison of the estimated and measured wind speed ratio between $50 \mathrm{~m}$ and $30 \mathrm{~m}$ height. For turbine design often a power law profile is used. This does not account for stability effects, which is shown to be a drawback, as these strongly influence the wind shear. From the measurements at Rødsand it can be seen that the power law profile proposed in the current IEC certification guidelines [34] underestimates the wind shear for stable stratification, especially in conditions with an 
elevated inversion layer, which lead to an increased wind shear compared to MoninObukhov theory. For load calculations it is also important to note that in offshore conditions flow with stable stratification occurs also at comparably high wind speeds. However, the influence of the wind speed itself on the wind shear is found to be less important for the wind speed range present in the data set.

Data measured at Rødsand are not sufficient to study the effect of the sea surface roughness on wind shear in extreme wind cases. For high wind speeds the surface roughness will increase according to the Charnock relation and possibly additionally due to the fetch limited wave field.

Currently these conclusions can be drawn for the site Rødsand only and need to be validated with other measurements. But from this example it can be seen that the flow modification in conditions of warm air advection from land plays an important role in the flow regime at offshore sites. At Rødsand this is the dominating uncertainty in the description of the wind conditions. Other sources of uncertainties, like the derivation of L, cannot be understood without taking this into account. We expect that a better understanding of this effect is a prerequisite for future improvements in the description of the wind regime over the coastal zone.

To improve the wind resource estimation for offshore sites, a model for the flow regime in conditions of warm air advection from land over sea is needed. The simple correction method introduced in this paper is intended to show the importance of the effect, but cannot be used as a general model of the flow regime. Further development with data from additional sites is needed. Until such a model is available, measurements at or close to hub height are necessary for an accurate estimation of the wind resource of an offshore location. 


\section{Acknowledgement}

The original instrumentation and maintenance of the Rødsand measurement station were funded by the EU-JOULE program and the Danish Energy Ministry's UVE program 'Offshore Wind Resources'. Subsequent instrumentation, operation and maintenance were funded by SEAS Distribution A.m.b.A (now Energi E2 A/S). The technical support team at Risø, particularly Ole Frost Hansen, are acknowledged for their contribution to the data collection. Mr Kobbernagel of Sydfalster-El preformed the maintenance and data collection at Rødsand.

\section{References}

[1] J.A. Businger, J.C. Wyngaard, Y. Izumi, E.F. Bradley, Flux-profile relationships in the atmospheric surface layer, J. Atmos. Sci. 28 (1971) 181189.

[2] H. Charnock, Wind stress over a water surface, Quart. J. Roy. Meteor. Soc. 81 (1955) 639-640.

[3] H.K. Johnson, J. Højstrup, H.J. Vested, S.E. Larsen, On the dependence of sea surface roughness on wind waves, J. Phys. Oceanogr. 28 (1998) 1702-1716.

[4] P.K. Taylor, M.J. Yelland, The dependence of sea surface roughness on the height and steepness of the waves, J. Phys. Oceanogr. 31 (2001) 572-590.

[5] B. Lange, J. Højstrup, S.E. Larsen, R.J. Barthelmie, A fetch dependent model of sea surface roughness for offshore wind power utilisation, in: P. Helm, A. Zervos (eds.), Wind Energy for the new millennium. Proceedings of the European Wind Energy Conference (Copenhagen 2001), WIP, Munich and ETA, Florenz, 2001. pp. 830-833. 
[6] J.R. Garratt, The atmospheric boundary layer. Cambridge University Press, Cambridge, 1994.

[7] A.A. Grachev, C.W. Fairall, Dependence of the Monin-Obukhov stability parameter on the bulk Richardson number over the ocean, J. Appl. Meteor. 36 (1997) 406-414.

[8] J.B. Edson, C.W. Fairall, Similarity relationships in the marine atmospheric surface layer for terms in the TKE and scalar variance budgets, J. Atmos. Sci. 55 (1998) 2311-2328.

[9] B. Källstrand, H. Bergström, J. Højstrup, A.-S. Smedman, Mesoscale wind field modifications over the Baltic Sea, Bound.-Layer Meteor. 95 (2000) 161188.

[10] H.P. Frank, S.E. Larsen, J. Højstrup, Simulated wind power off-shore using different parameterisations for the sea surface roughness, Wind Energy 3(2) (2000) 67-79.

[11] G.T. Csanady, Equilibrium theory of the planetary boundary layer with an inversion lid, Bound.-Layer Meteor. 6 (1974) 63-79.

[12] I. Troen, E. L. Petersen, European wind atlas. Risø National Laboratory, Roskilde, Denmark, 1989.

[13] N.G. Mortensen, L. Landberg, I. Troen, E.L. Petersen, Wind analysis and application program (WASP) - User's guide. Report Risø-I-666(EN) (v.2), Risø National Laboratory, Roskilde, Denmark, 1993.

[14] H.G. Matthies, A.D. Garrad, Study of offshore wind energy in the EC. Executive summary. Report: Joule 1 (JOUR 0072), Germanischer Lloyd Wind 
Energy, Hamburg, 1993.

[15] A. Lavagnini, S. Martorelli, L. Cavaleri, The wind climatology of the Adriatic Sea deduced from coastal stations, Il Nuovo Cimento 19(C1) (1996) 37-50.

[16] J.A. Halliday, G.M. Watson, J.P. Palutikof, T. Holt, R.J. Barthelmie, J.P. Coelingh, L. Folkerts, E.J.v. Zuylen, J.W. Cleijne, POWER - A methodology for predicting offshore wind energy resources, in: P. Helm, A. Zervos (eds.), Wind Energy for the new millennium. Proceedings of the European Wind Energy Conference (Copenhagen 2001), WIP, Munich and ETA, Florenz, 2001. pp. $785-788$.

[17] L. Enger, Simulation of dispersion in a moderately complex terrain. Part A. The fluid dynamic model, Atmos. Environ. 24A (1990) 2431-2446.

[18] H. Bergström, R. Barthelmie, Offshore boundary-layer modelling. in: Proceedings of the Global Windpower Conference (Paris 2002), EWEA, Brussels, published on CD.

[19] B. Lange, J. Højstrup, Evaluation of the wind-resource estimation program WAsP for offshore applications, Journal of Wind Engineering and Industrial Aerodynamics 89 (2001) 271-291.

[20] B. Lange, R.J. Barthelmie, J. Højstrup, Description of the Rødsand field measurement, Report Ris $\emptyset-\mathrm{R}-1268$, Ris $\varnothing$ National Laboratory, Roskilde, Denmark, 2001.

[21] B. Lange, S. Larsen, J. Højstrup, R. Barthelmie, The influence of thermal effects on the wind speed profile of the coastal marine boundary layer, Bound.Layer Meteor. Manuscript accepted for publication. 
[22] B. Lange, Modelling the marine boundary layer for offshore wind power utilisation. VDI Verlag, Düsseldorf, 2002.

[23] J. Højstrup, Vertical extrapolation of offshore windprofiles. in: E.L. Petersen, P. Hjuler Jensen, K. Rave, P. Helm, H. Ehmann (eds.), Wind energy for the next millennium. Proceedings of the European wind energy conference EWEC '99 (Nice 1999), James and James, London, 1999. pp. 1220-1223.

[24] P. Schotanus, Temperature measurement with a sonic anemometer and its application to heat and moisture fluxes, Bound.-Layer Meteor. 26 (1983) 8193.

[25] G. Geernaert, S. Larsen, On the role of humidity in estimating marine surface layer stratification and scaterometer cross section, J. Geophys. Res. 98(C1) (1993) 927-932.

[26] S.E. Larsen, Observing and modelling the planetary boundary layer. in: E. Raschke, D. Jacob (eds.), Energy and water cycles in the climate system. NATO ASI series I, volume 5, Springer-Verlag, Berlin, Heidelberg, 1993. pp. $365-418$.

[27] U. Högström, Nondimensional wind and temperature profiles, Bound.-Layer Meteor. 42 (1988) 55-78.

[28] C.W. Fairall, E.F. Bradley, J.S. Godfrey, G.A. Wick, J.B. Edson, G.S. Young, Cool-skin and warm-layer effects on sea surface temperature, J. Geophys. Res. 101(C1) (1996) 1295-1308.

[29] J. Wu, Wind-stress coefficients over sea surface near neutral conditions - A revisit, J. Phys. Oceanogr. 10 (1980) 727-740. 
[30] K.K. Kahma, C.J. Calkoen, Reconciling discrepancies in the observed growth of wind-generated waves, J. Phys. Oceanogr. 22 (1992) 1389-1405.

[31] A.S. Smedman, H. Bergström, B. Grisogono, Evolution of stable internal boundary layers over a cold sea, J. Geophys. Res. 102(C1) (1997) 1091-1099.

[32] M. Tjernström, A.-S. Smedman, The vertical turbulence structure of the coastal marine atmospheric boundary layer, J. Geophys. Res. 98(C3) (1993) 4809-4826.

[33] B. Lange, H.K. Johnson, S. Larsen, J. Højstrup, H. Kofoed-Hansen, On detection of a wave age dependency for the sea surface roughness, J. Phys. Oceanogr. Manuscript accepted for publication.

[34] IEC-61400-1: Wind turbine generator systems part 1: Safety requirements. International Electrotechnical Commission, Geneva, Swiss, 1998. 


\section{Figure captions}

Figure 1: Map of the measurement stations

Figure 2: Deviation $\mathrm{R}$ between measured and predicted $50 \mathrm{~m}$ wind speeds versus $10 \mathrm{~m} / \mathrm{L} ; \mathrm{L}$ derived with the gradient method and $\mathrm{z}_{0}$ with the Charnock model

Figure 3: Bin-averaged ratio $\mathrm{R}$ of measured and predicted $50 \mathrm{~m}$ wind speed versus stability parameter $10 \mathrm{~m} / \mathrm{L}$ with $\mathrm{L}$ determined by the sonic, gradient and bulk methods and $\mathrm{z}_{0}$ with Charnock model

Figure 4: Bin-averaged ratio of measured and predicted $50 \mathrm{~m}$ wind speed versus stability parameter $10 \mathrm{~m} / \mathrm{L}$ with $\mathrm{L}$ determined by the bulk method and $\mathrm{z}_{0}$ modelled with four different models (see text)

Figure 5: Bin-averaged ratio of measured and predicted $50 \mathrm{~m}$ wind speed versus wind speed at $10 \mathrm{~m}$ height with $\mathrm{L}$ determined by the bulk method and $\mathrm{z}_{0}$ modelled with four different models (see text)

Figure 6: Conceptual sketch of the flow regime with warm air advection over colder sea. The wind profile is shown compared with a neutral profile.

Figure 7: Deviation R bin averaged for the estimated height of inversion layer $\mathrm{h}$ (from eq. (15)); When estimating u50 $0_{\text {pred, }}$, the bulk method has been used to determine $\mathrm{L}$ and the Charnock equation for the estimation of $\mathrm{z}_{0}$

Figure 8: Bin-averaged ratio of measured and predicted $50 \mathrm{~m}$ wind speed versus stability parameter $10 \mathrm{~m} / \mathrm{L}$ with $\mathrm{L}$ determined by the sonic, gradient and bulk methods and $\mathrm{z}_{0}$ with Charnock model; the proposed correction method for thermal influences is used 
Figure 9: Bin-averaged ratio of measured and predicted $50 \mathrm{~m}$ wind speed versus wind speed at $10 \mathrm{~m}$ height with $\mathrm{L}$ determined by the bulk method and $\mathrm{z}_{0}$ modelled with four different models (see text); the proposed correction method for thermal influences is used

Figure 10: Power curve of the example wind turbine

Figure 11: Error in power output prediction $\left(\mathrm{P}_{\text {meas }}-\mathrm{P}_{\text {pred }}\right) / \mathrm{P}_{\text {meas }}$ of an example turbine for the Rødsand data set; different methods to extrapolate the wind speed measurement at $10 \mathrm{~m}$ height to $50 \mathrm{~m}$ are used (see text)

Figure 12: Difference between predicted and measured power output, bin averaged for stability parameter $10 \mathrm{~m} / \mathrm{L}$; L derived with Sonic, Gradient and Bulk methods; Prediction with and without wind profile correction

Figure 13: Difference between predicted and measured power output, bin averaged for $10 \mathrm{~m}$ wind speed; Comparison of different models with wind profile correction

Figure 14: Relative error in power output prediction $\left(\mathrm{P}_{\text {meas }}-\mathrm{P}_{\text {pred }}\right) / \mathrm{P}_{\text {meas }}$ of an example turbine for the 2 year long Rødsand data set; different methods to extrapolate the wind speed measurement at $10 \mathrm{~m}$ height to $50 \mathrm{~m}$ are used (see text); the result with the WAsP method is also shown

Figure 15: Comparison of wind speed (left) and wind shear (right) height profiles for different profile forms; the wind speed at hub height $80 \mathrm{~m}$ is $10 \mathrm{~m} / \mathrm{s}$; shown are a power law profile with $\mathrm{a}=0.2$, a logarithmic profile with $\mathrm{z}_{0}=0.0002 \mathrm{~m}$, a MoninObukhov profile with $\mathrm{z}_{0}=0.0002 \mathrm{~m}$ and $\mathrm{L}=200 \mathrm{~m}$, and a profile with inversion layer correction from eq. (16) with $\mathrm{z}_{0}=0.0002 \mathrm{~m}, \mathrm{~L}=200 \mathrm{~m}$ and $\mathrm{h}=200 \mathrm{~m}$

Figure 16: Wind speed ratio between $50 \mathrm{~m}$ and $30 \mathrm{~m}$ height measured at Rødsand versus atmospheric stability; also shown are calculations with different wind speed profiles (see Figure 15) 
Figure 17: Wind speed ratio between $50 \mathrm{~m}$ and $30 \mathrm{~m}$ height measured at Rødsand versus wind speed at $10 \mathrm{~m}$ height for different stability classes $(10 \mathrm{~m} / \mathrm{L}<-0.05$ unstable, $-0.05<10 \mathrm{~m} / \mathrm{L}<0.05$ near-neutral, $10 \mathrm{~m} / \mathrm{L}>0.05$ stable stratification); also shown are calculations with different wind speed profiles (see Figure 15)

Figure 18: As in Figure 17, but bin averaged data with respect to wind speed 


\section{Table captions}

Table 1: Instrumentation of the Rødsand measurement

Table 2: Synoptic stations used for estimating the upwind air temperature over land 


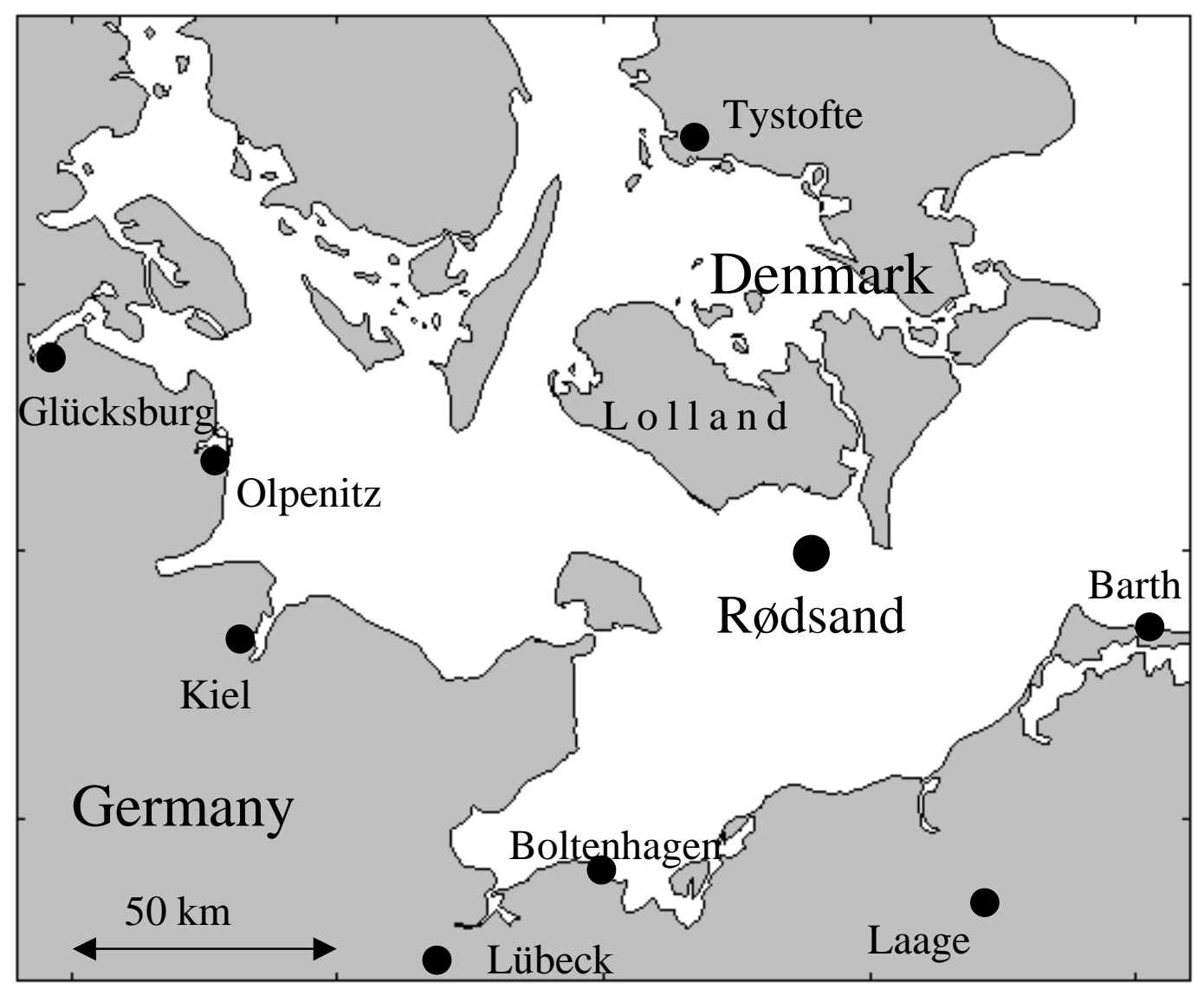

Figure 1: Map of the measurement stations 


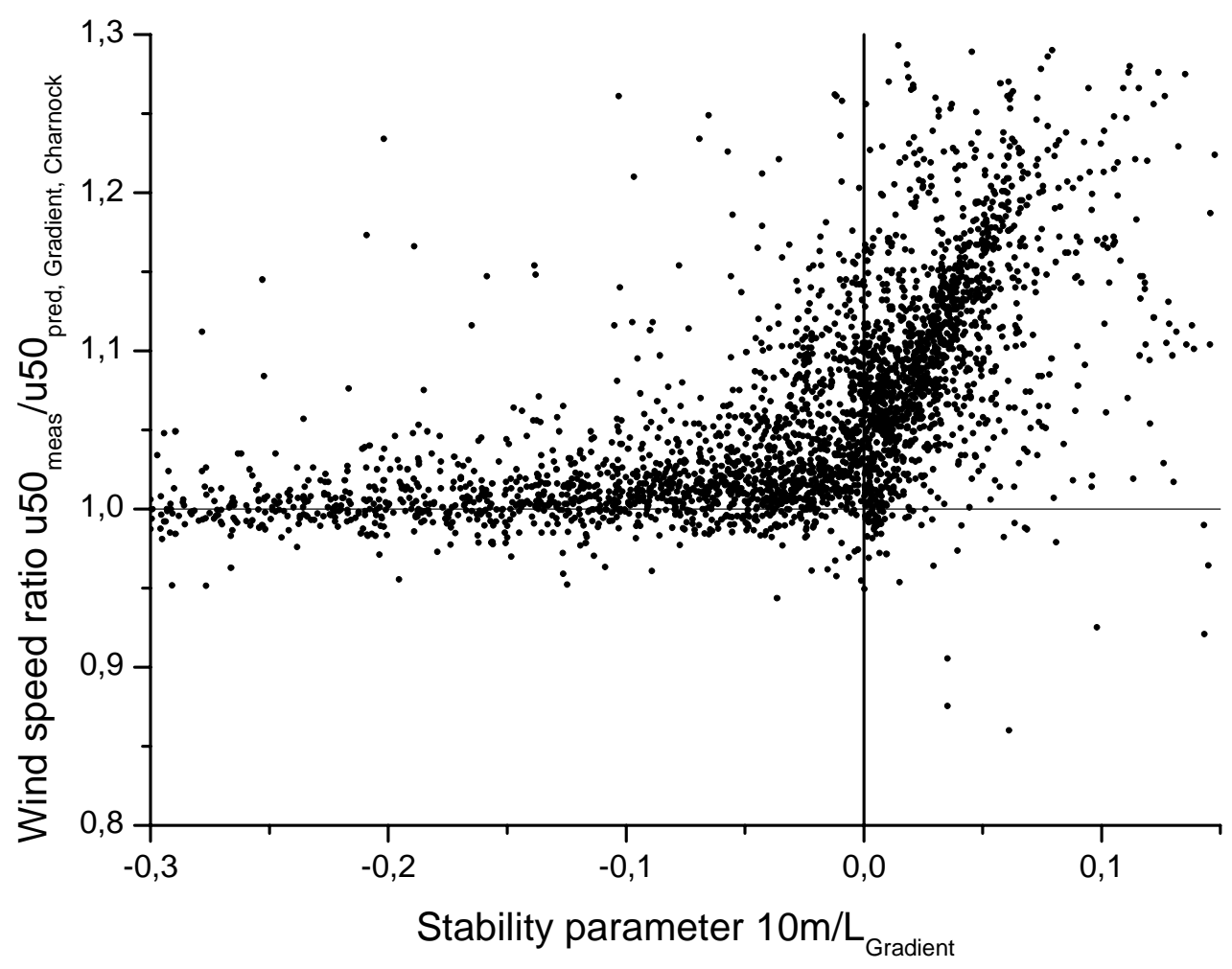

Figure 2: Deviation $R$ between measured and predicted $50 \mathrm{~m}$ wind speeds versus $10 \mathrm{~m} / \mathrm{L} ;$ L derived with the gradient method and $z_{0}$ with the Charnock model 


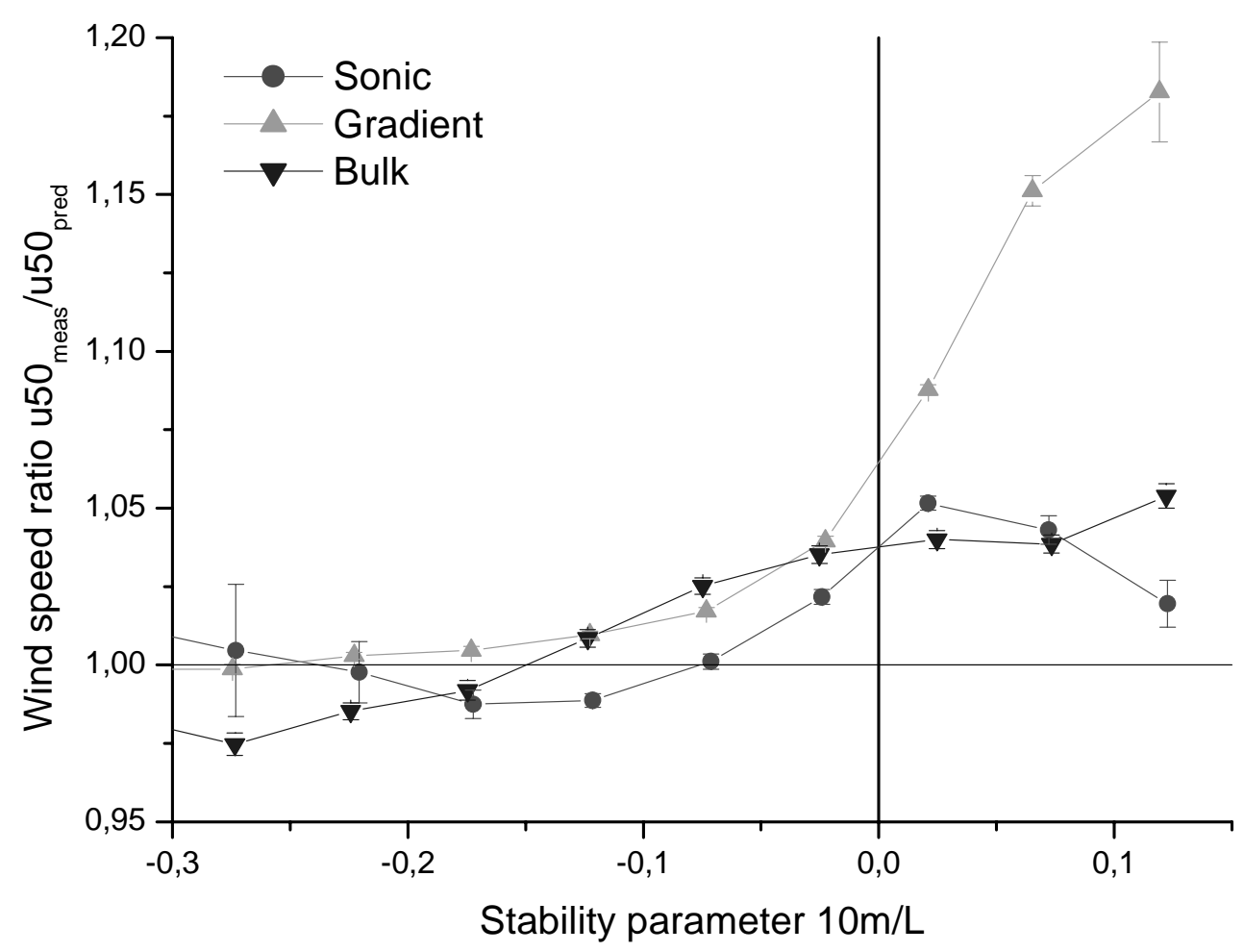

Figure 3: Bin-averaged ratio $R$ of measured and predicted $50 \mathrm{~m}$ wind speed versus stability parameter $10 \mathrm{~m} / \mathrm{L}$ with $L$ determined by the sonic, gradient and bulk methods and $z_{0}$ with Charnock model 


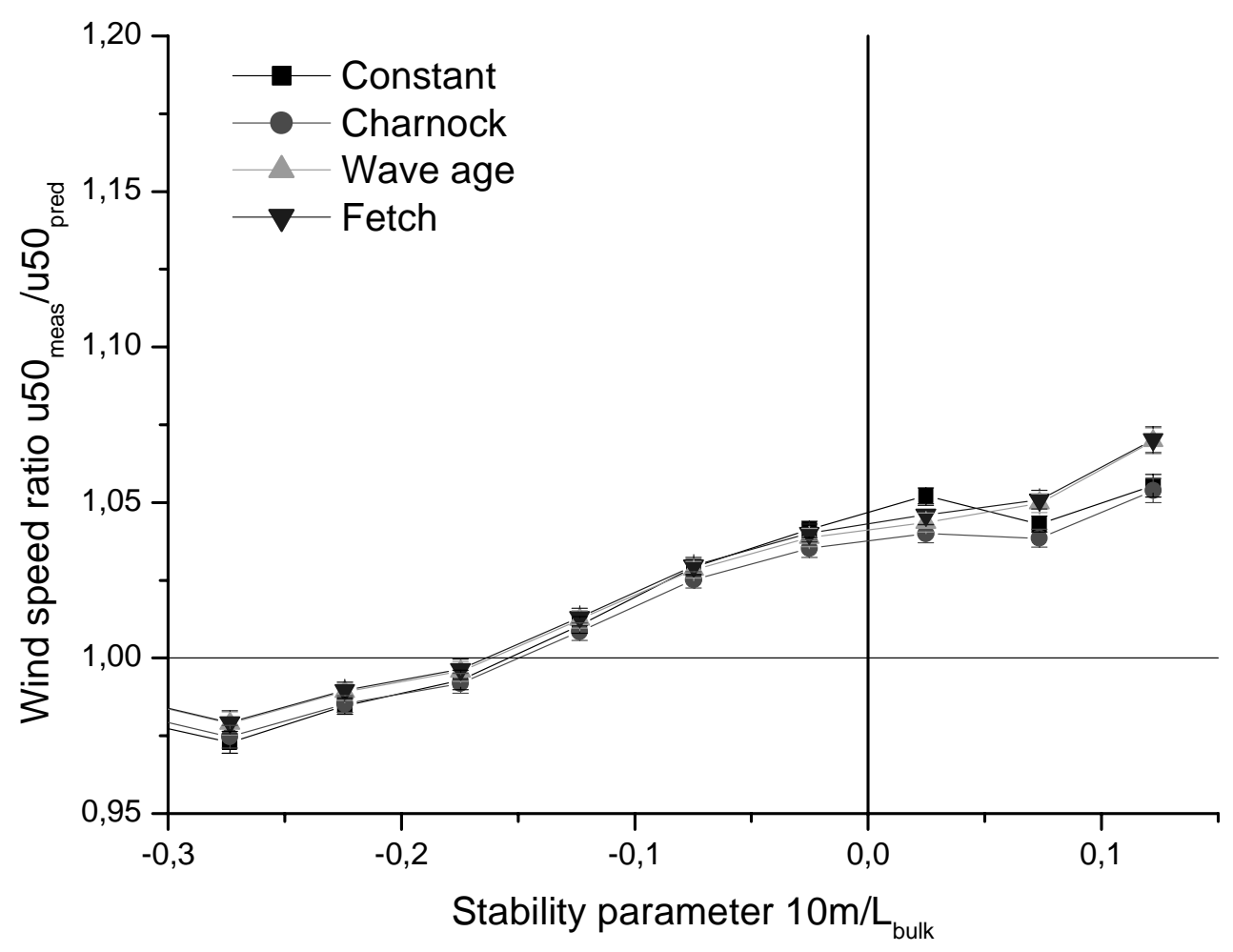

Figure 4: Bin-averaged ratio of measured and predicted $50 \mathrm{~m}$ wind speed versus stability parameter $10 \mathrm{~m} / \mathrm{L}$ with $\mathrm{L}$ determined by the bulk method and $z_{0}$ modelled with four different models (see text) 

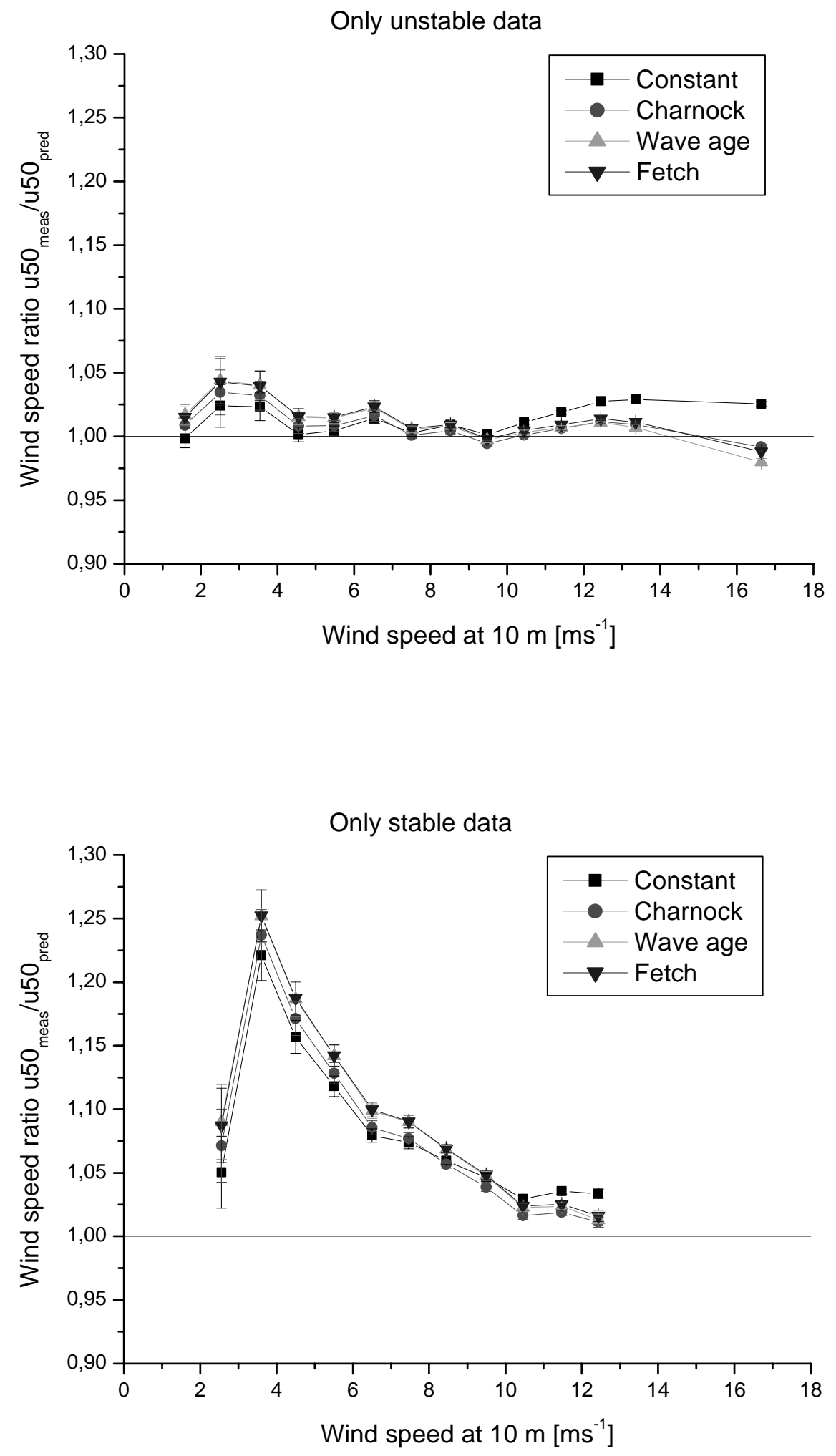

page 47 of 64 
Figure 5: Bin-averaged ratio of measured and predicted $50 \mathrm{~m}$ wind speed versus wind speed at $10 \mathrm{~m}$ height with $L$ determined by the bulk method and $z_{0}$ modelled with four different models (see text) 


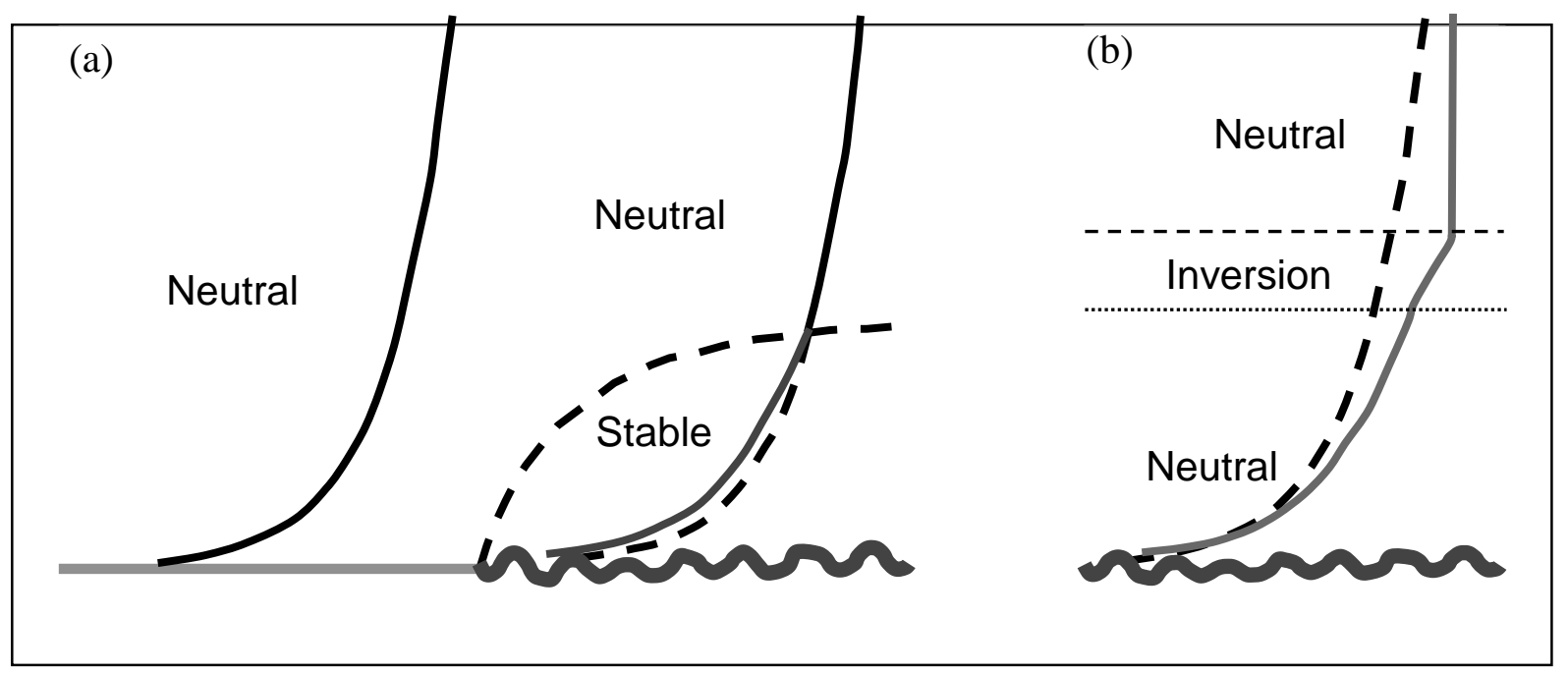

Figure 6: Conceptual sketch of the flow regime with warm air advection over colder sea. The wind profile is shown compared with a neutral profile. 


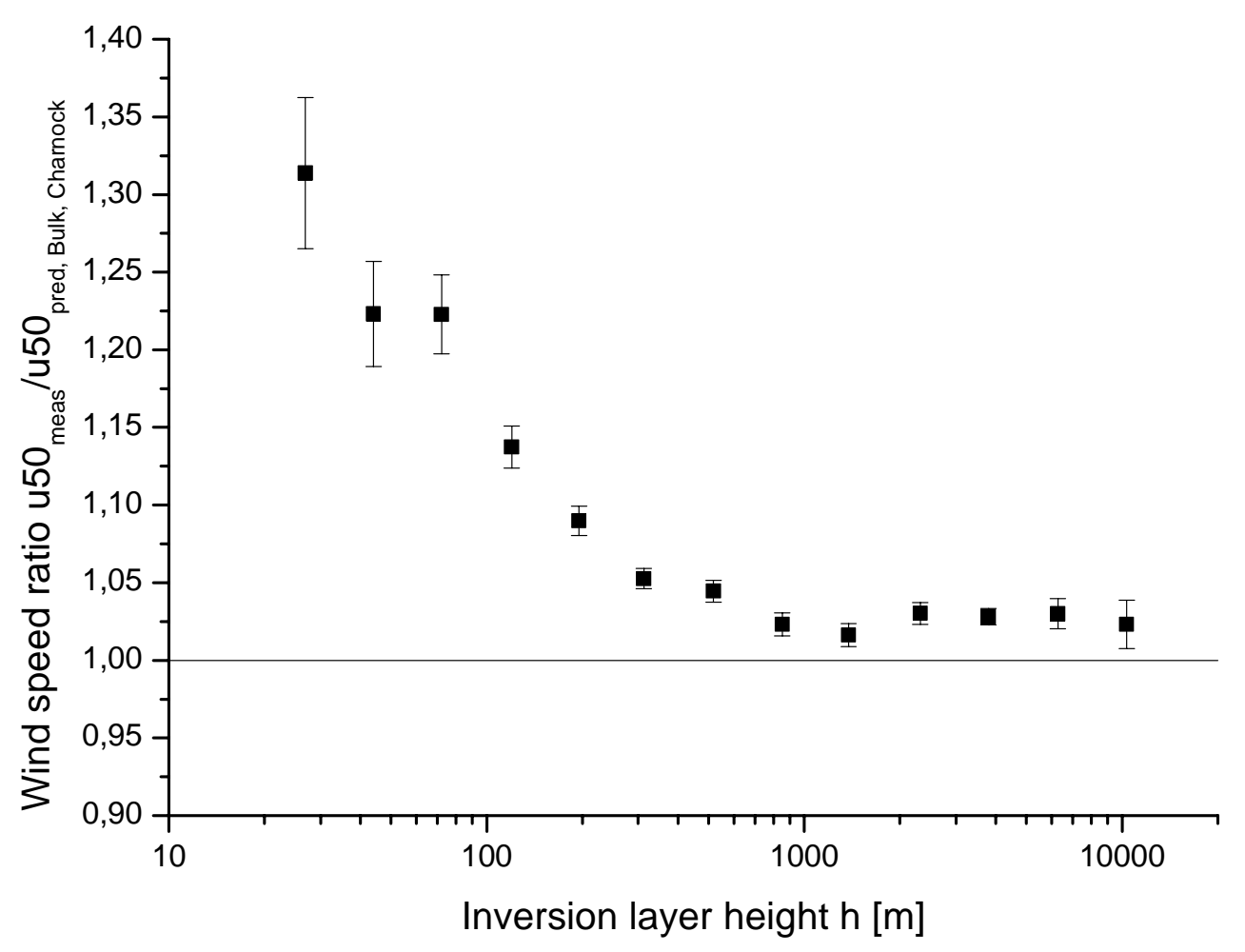

Figure 7: Deviation R bin averaged for the estimated height of inversion layer $h$ (from eq. (15)); When estimating $450_{\text {pred, }}$ the bulk method has been used to determine L and the Charnock equation for the estimation of $z_{0}$ 


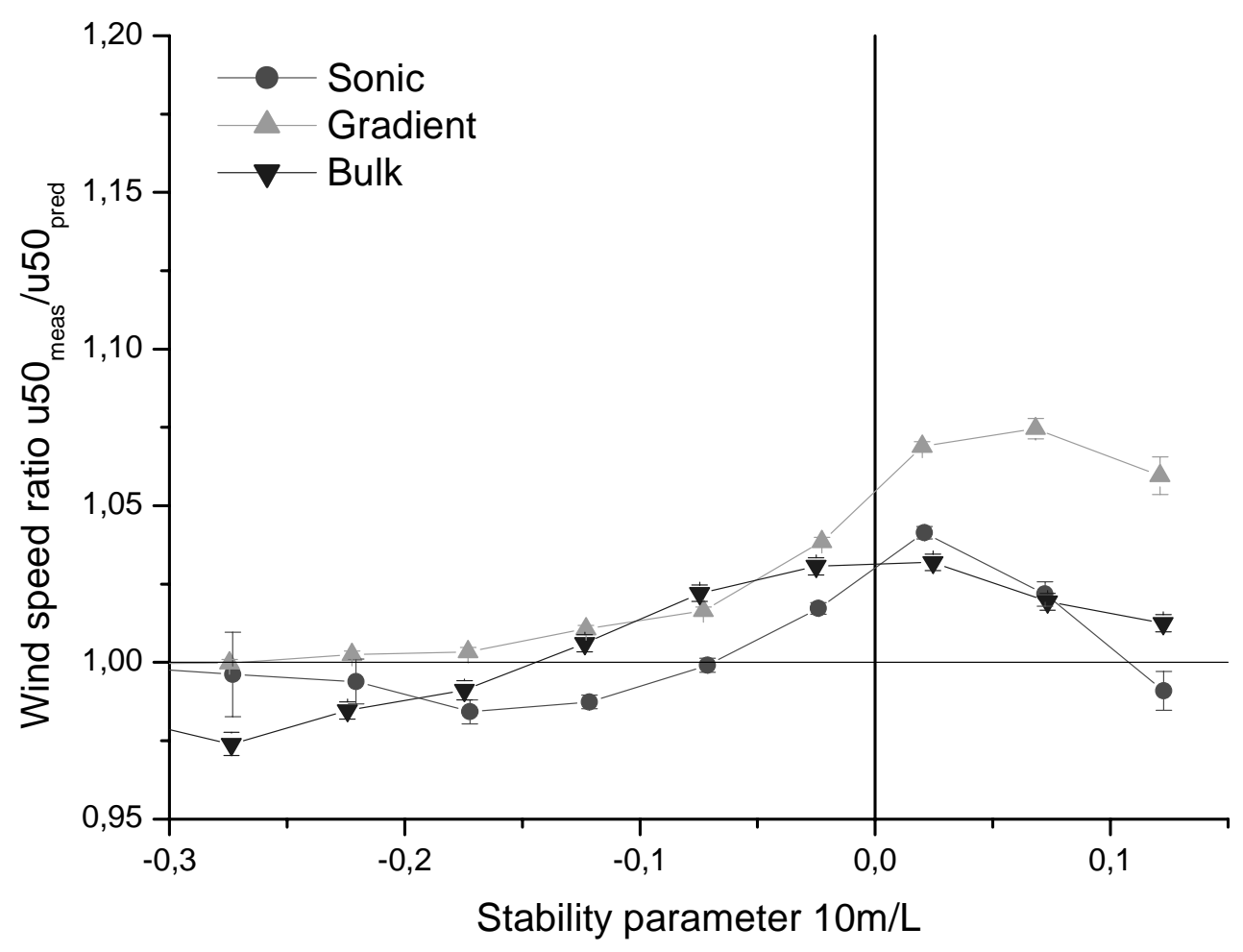

Figure 8: Bin-averaged ratio of measured and predicted $50 \mathrm{~m}$ wind speed versus stability parameter $10 \mathrm{~m} / \mathrm{L}$ with $L$ determined by the sonic, gradient and bulk methods and $z_{0}$ with Charnock model; the proposed correction method for thermal influences is used 

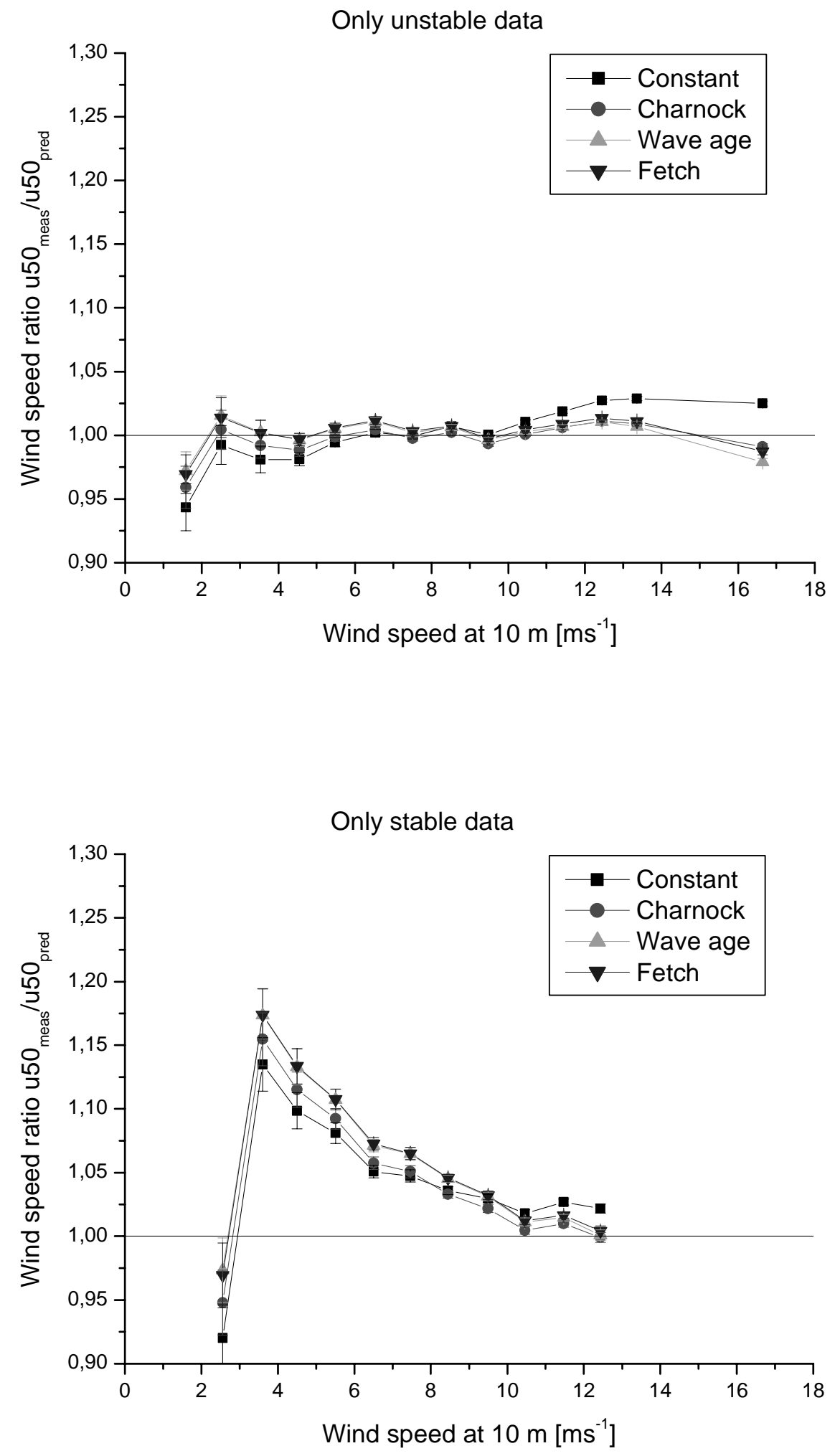

page 52 of 64 
Figure 9: Bin-averaged ratio of measured and predicted $50 \mathrm{~m}$ wind speed versus wind speed at $10 \mathrm{~m}$ height with $L$ determined by the bulk method and $z_{0}$ modelled with four different models (see text); the proposed correction method for thermal influences is used 


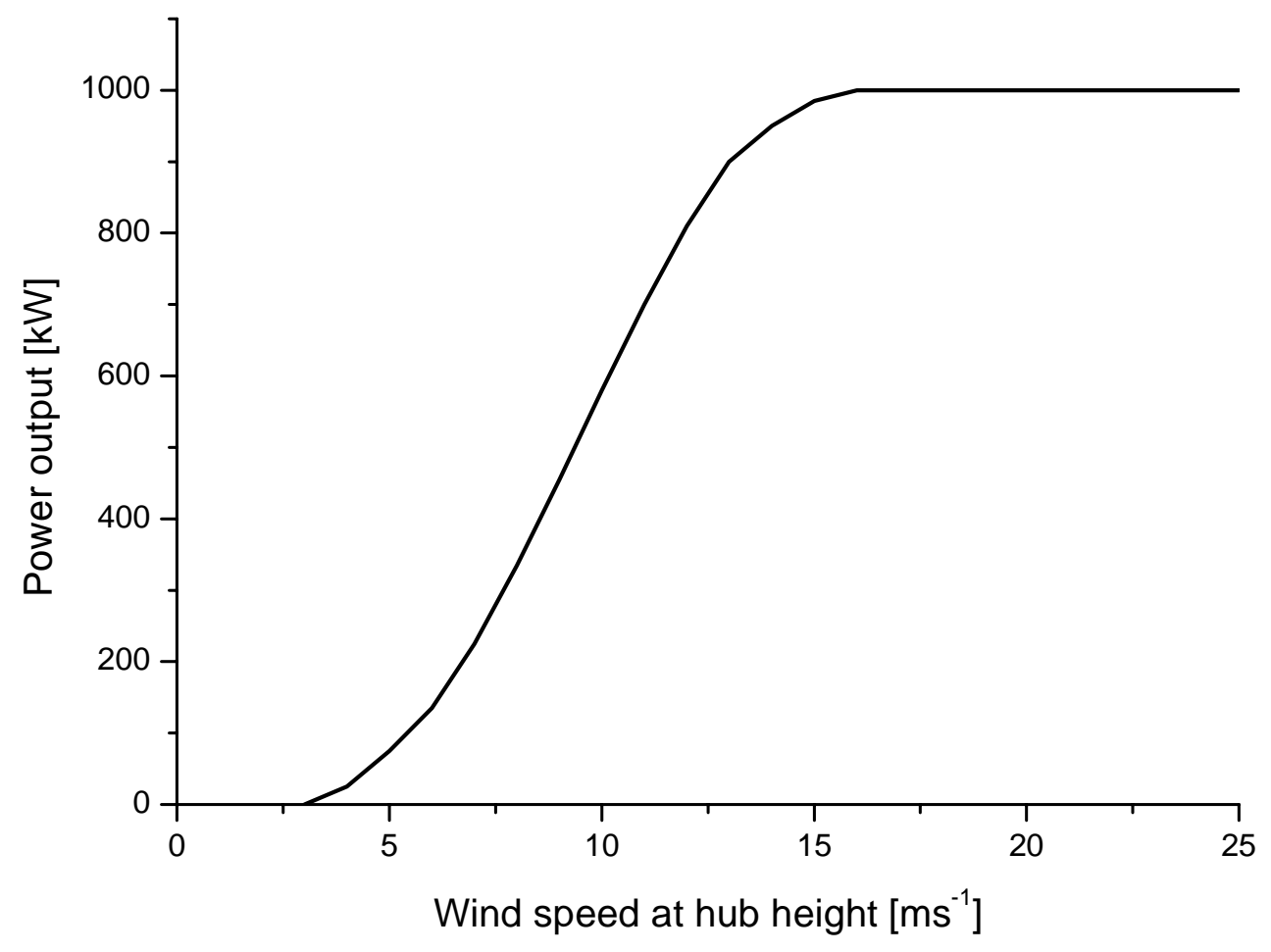

Figure 10: Power curve of the example wind turbine 


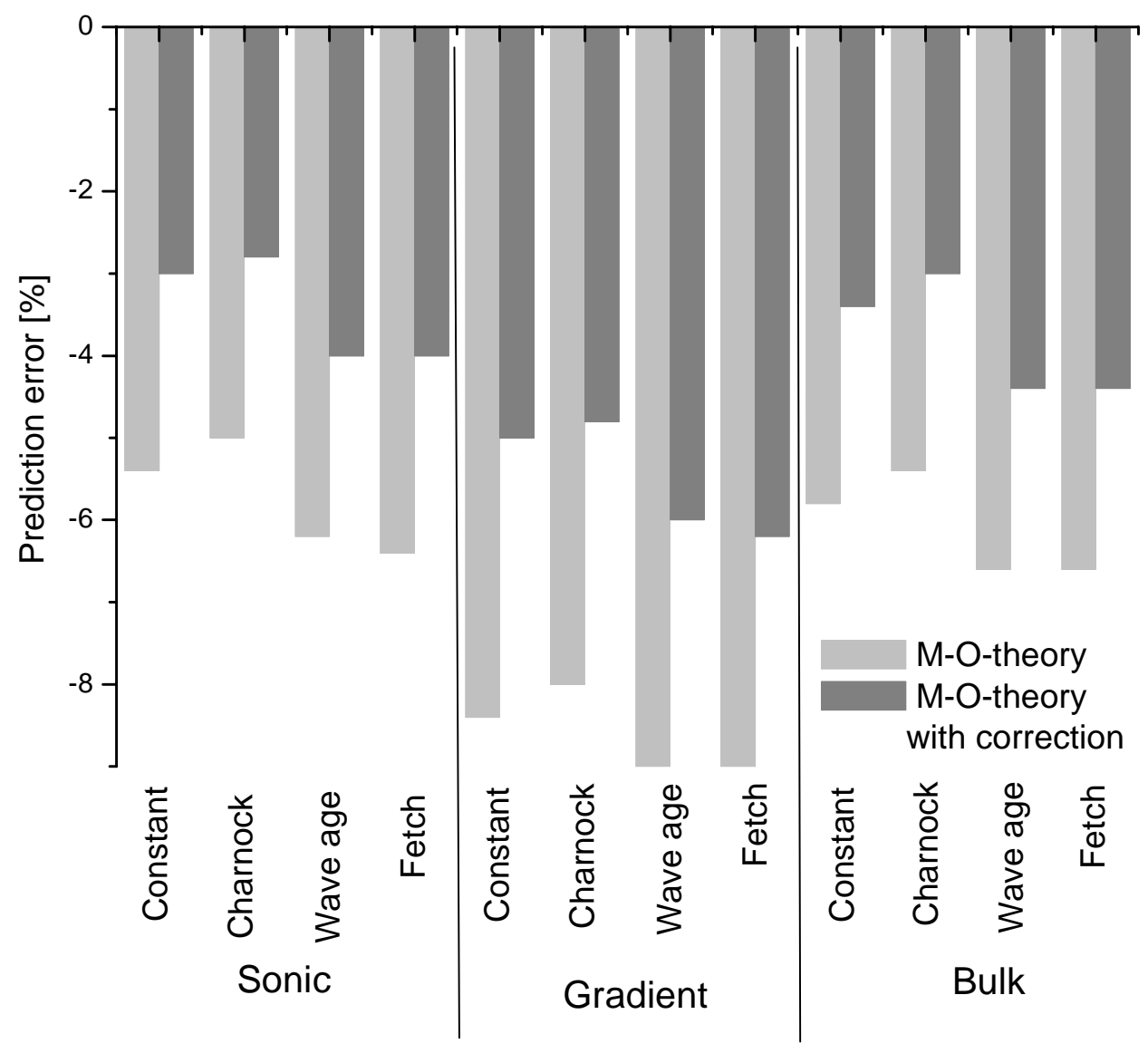

Figure 11: Error in power output prediction $\left(P_{\text {meas }}-P_{\text {pred }}\right) / P_{\text {meas }}$ of an example turbine for the Rødsand data set; different methods to extrapolate the wind speed measurement at $10 \mathrm{~m}$ height to $50 \mathrm{~m}$ are used (see text) 


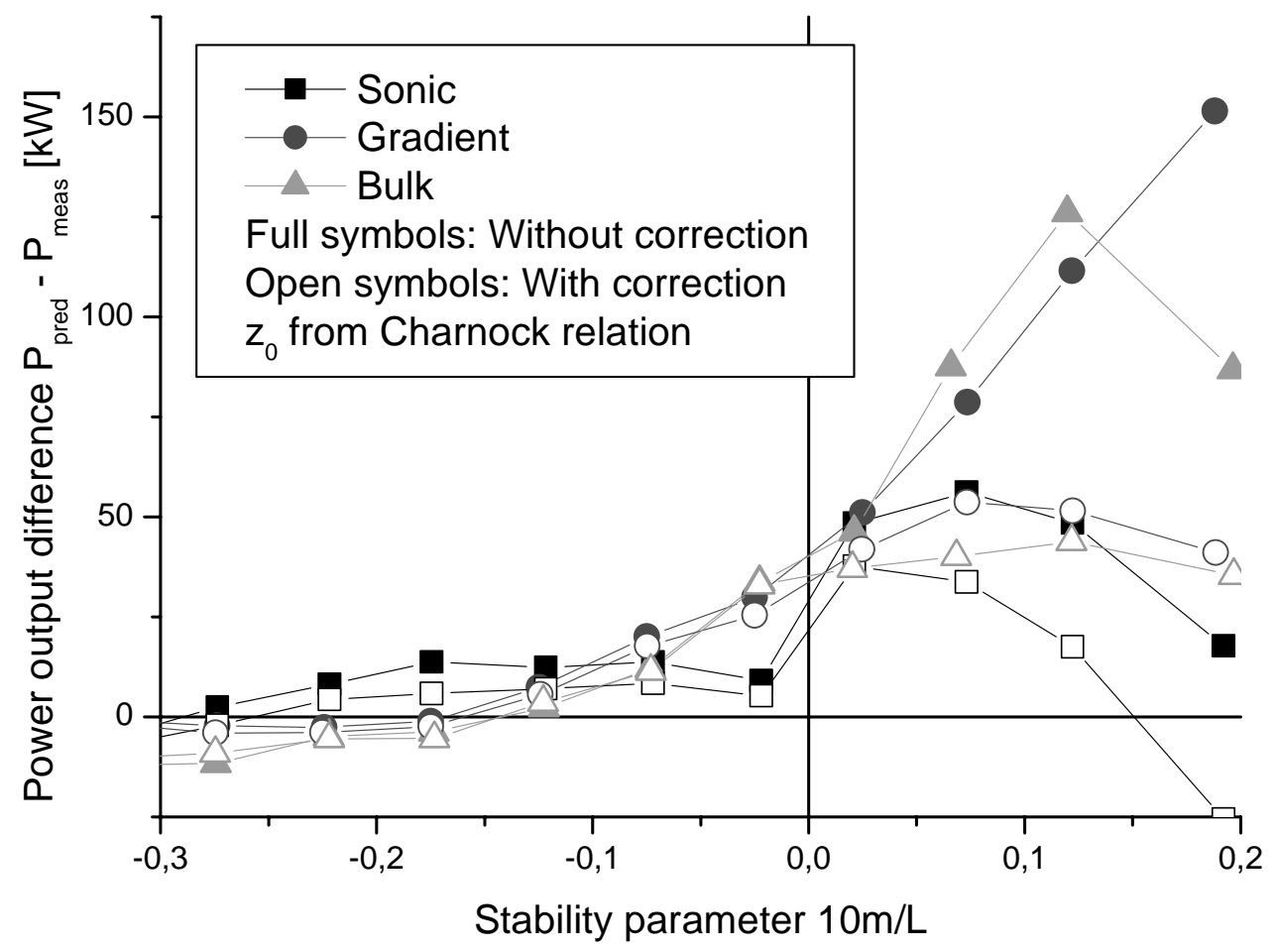

Figure 12: Difference between predicted and measured power output, bin averaged for stability parameter $10 \mathrm{~m} / \mathrm{L}$; L derived with Sonic, Gradient and Bulk methods; Prediction with and without wind profile correction 


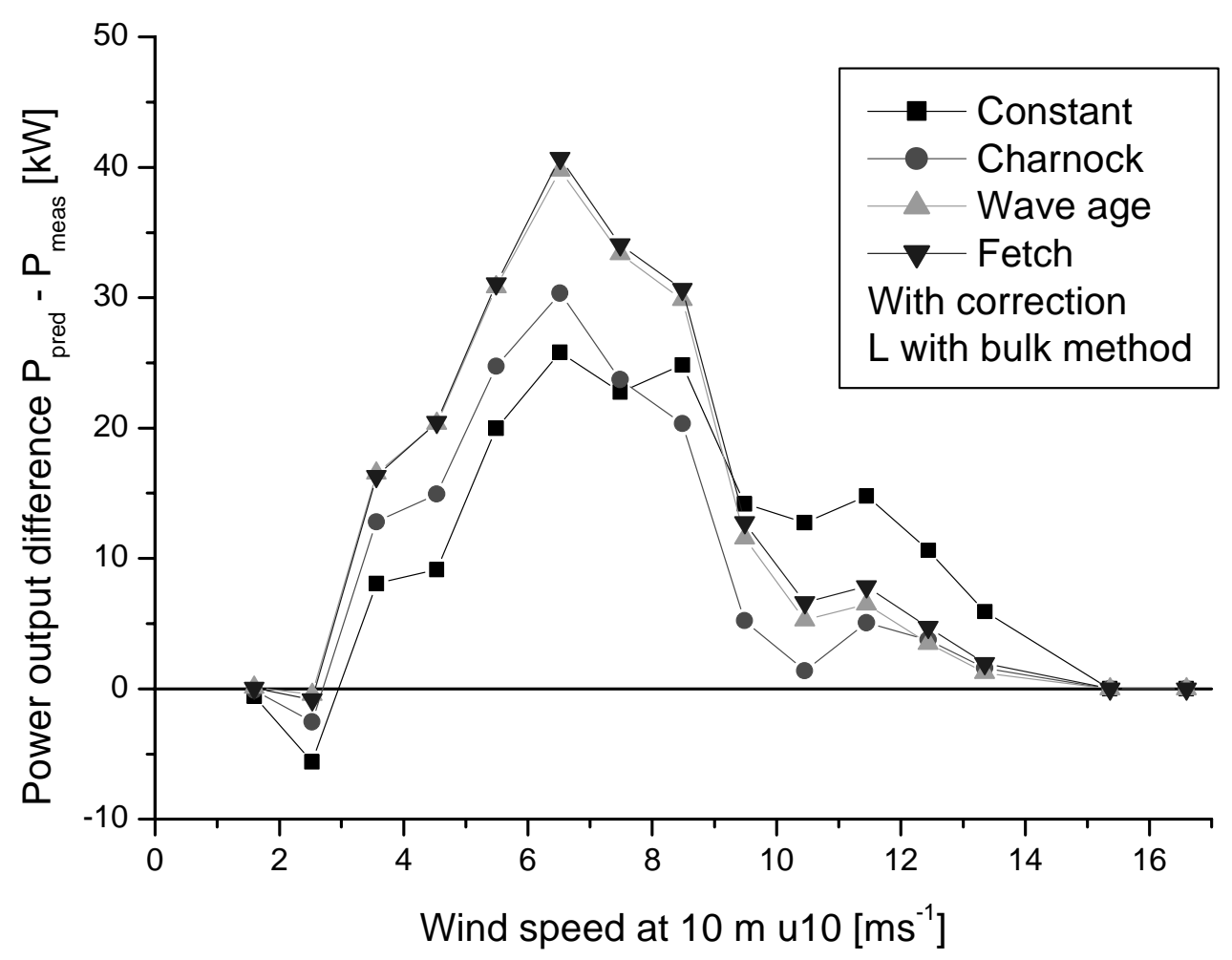

Figure 13: Difference between predicted and measured power output, bin averaged for $10 \mathrm{~m}$ wind speed; Comparison of different models with wind profile correction 


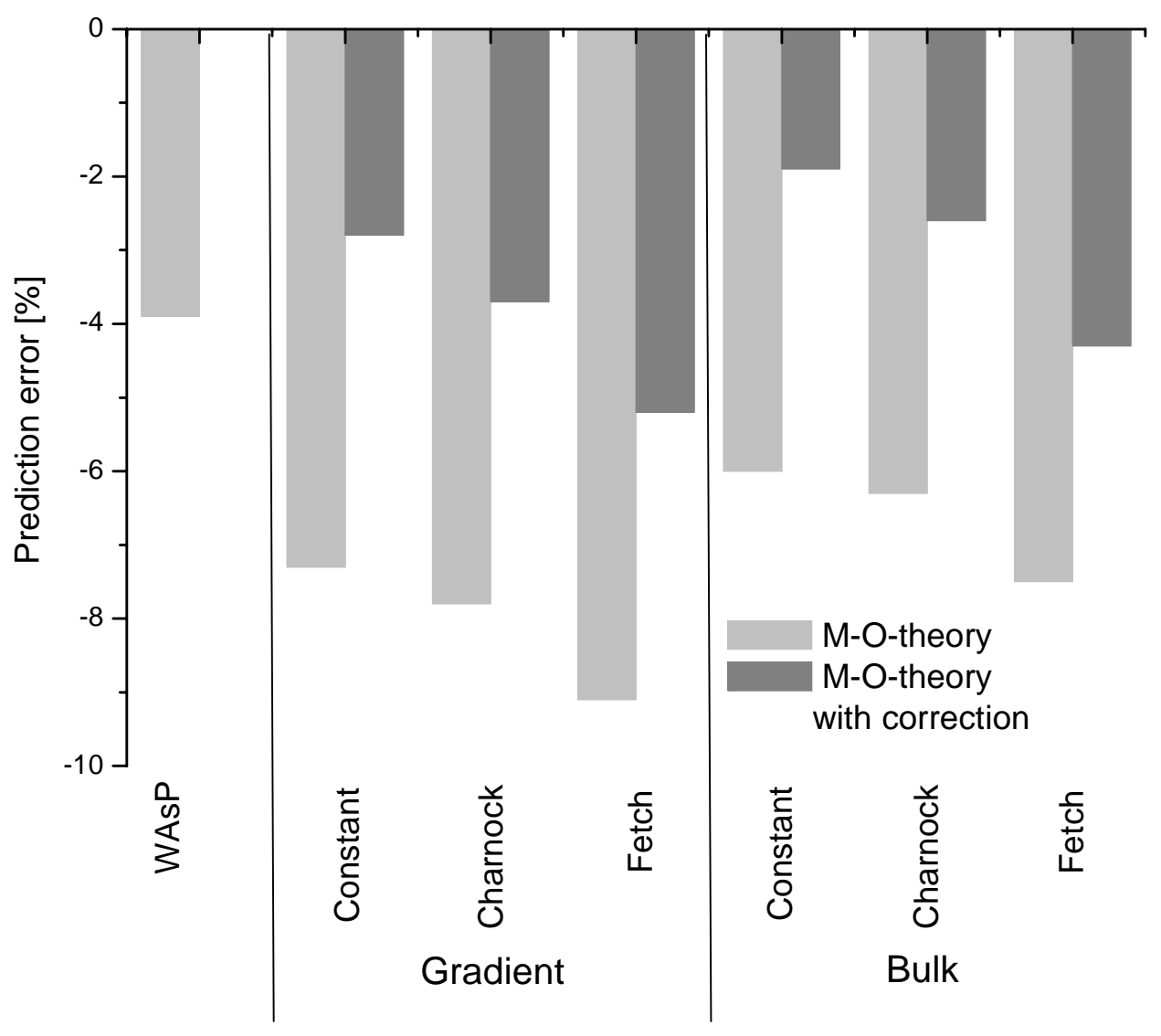

Figure 14: Relative error in power output prediction $\left(P_{\text {meas }}-P_{\text {pred }}\right) / P_{\text {meas }}$ of an example turbine for the 2 year long Rødsand data set; different methods to extrapolate the wind speed measurement at $10 \mathrm{~m}$ height to $50 \mathrm{~m}$ are used (see text); the result with the WAsP method is also shown 


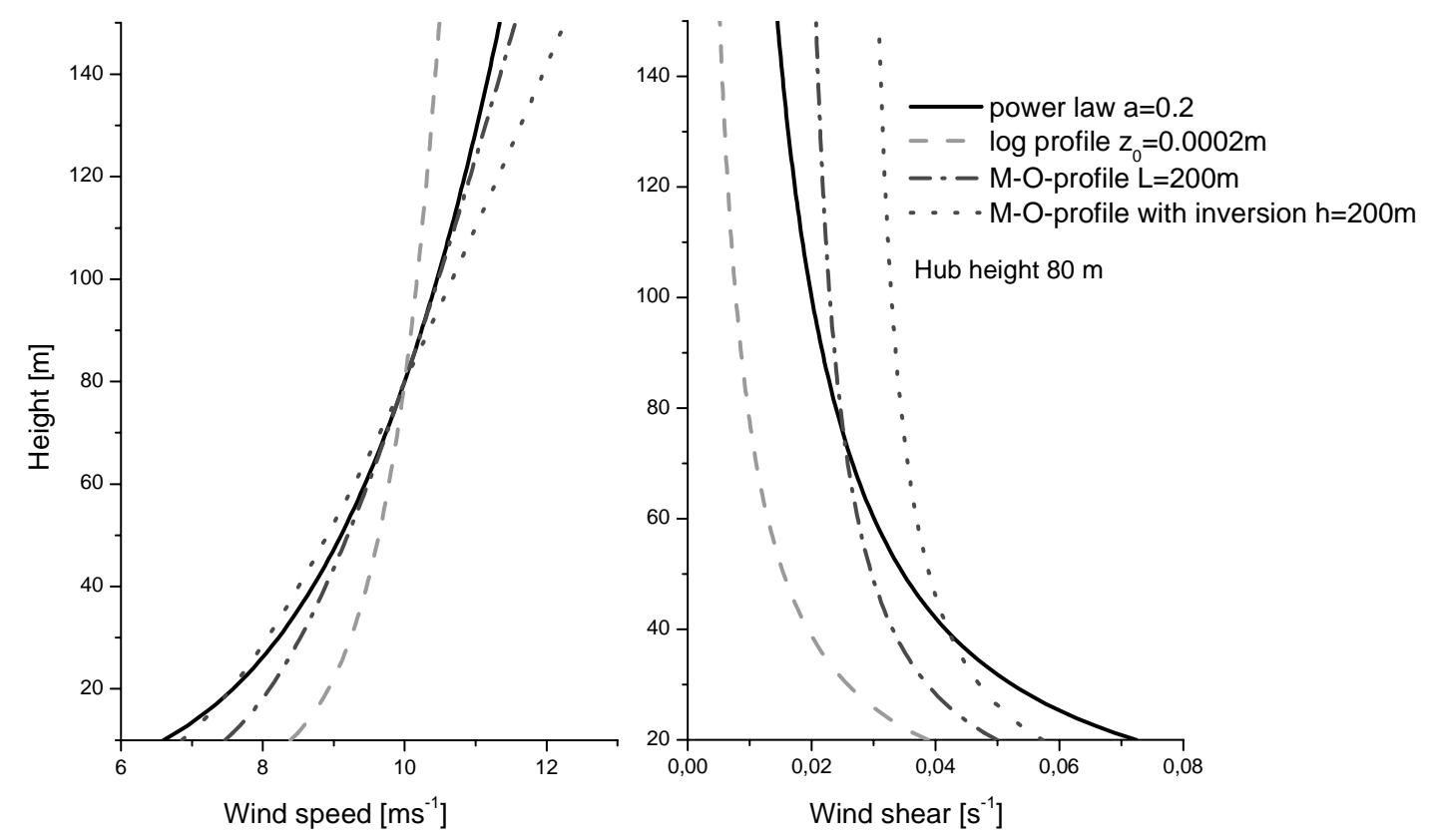

Figure 15: Comparison of wind speed (left) and wind shear (right) height profiles for different profile forms; the wind speed at hub height $80 \mathrm{~m}$ is $10 \mathrm{~ms}^{-1}$; shown are a power law profile with $a=0.2$, a logarithmic profile with $z_{0}=0.0002 m$, a MoninObukhov profile with $z_{0}=0.0002 \mathrm{~m}$ and $L=200 \mathrm{~m}$, and a profile with inversion layer correction from eq. (16) with $z_{0}=0.0002 \mathrm{~m}, L=200 \mathrm{~m}$ and $h=200 \mathrm{~m}$ 


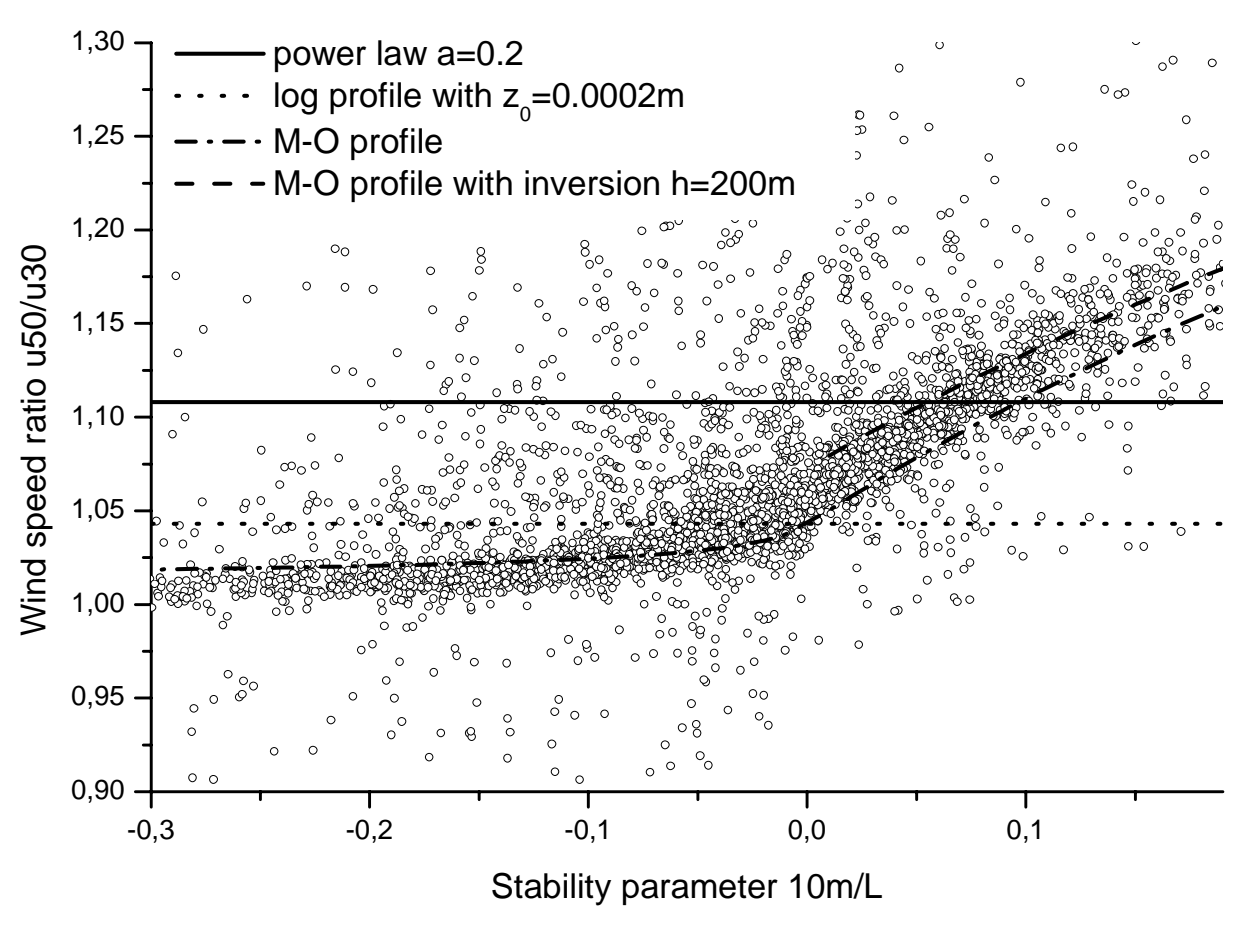

Figure 16: Wind speed ratio between $50 \mathrm{~m}$ and $30 \mathrm{~m}$ height measured at Rødsand versus atmospheric stability; also shown are calculations with different wind speed profiles (see Figure 15) 


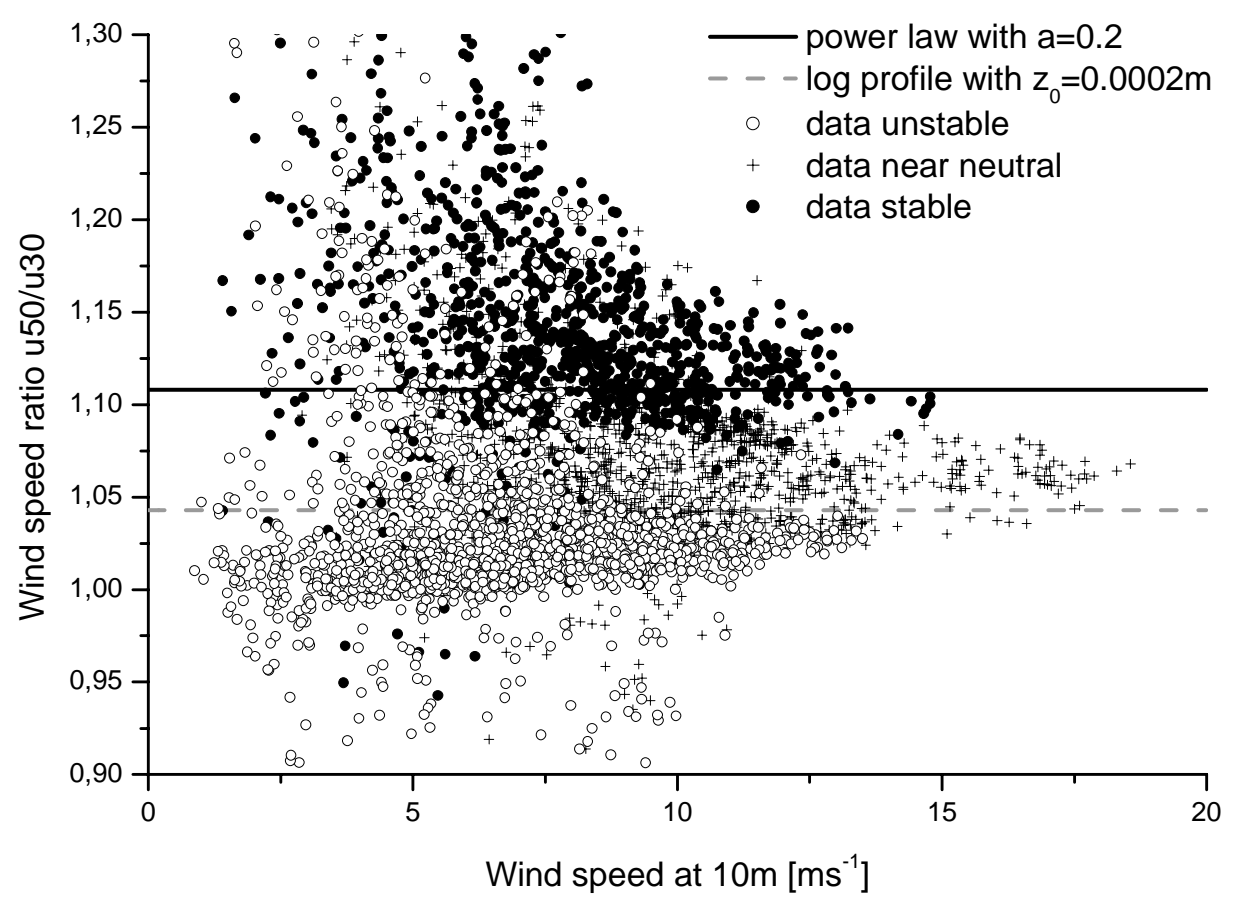

Figure 17: Wind speed ratio between $50 \mathrm{~m}$ and $30 \mathrm{~m}$ height measured at Rødsand versus wind speed at $10 \mathrm{~m}$ height for different stability classes $(10 \mathrm{~m} / L<-0.05$ unstable, $-0.05<10 \mathrm{~m} / \mathrm{L}<0.05$ near-neutral, $10 \mathrm{~m} / \mathrm{L}>0.05$ stable stratification); also shown are calculations with different wind speed profiles (see Figure 15) 


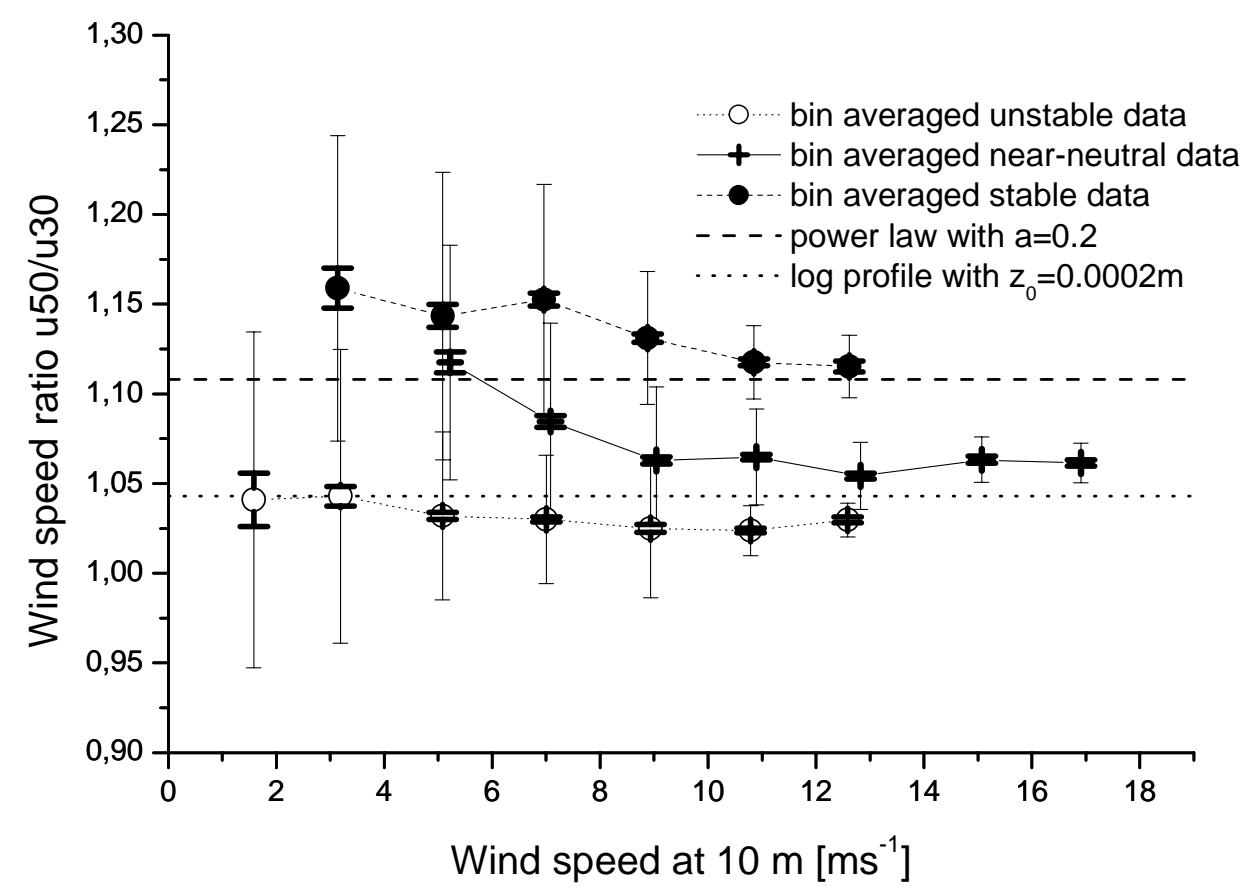

Figure 18: As in Figure 17, but bin averaged data with respect to wind speed 
Table 1: Instrumentation of the Rødsand measurement

\begin{tabular}{|c|c|c|c|}
\hline & $\begin{array}{l}\text { height above } \\
\text { mean sea level }\end{array}$ & instrument & sampling rate \\
\hline Wind speed & $50.3 \mathrm{~m}$ & cup anemometer & $5 \mathrm{~Hz}$ \\
\hline & $29.8 \mathrm{~m}$ & cup anemometer & $5 \mathrm{~Hz}$ \\
\hline & $10.2 \mathrm{~m}$ & cup anemometer & $5 \mathrm{~Hz}$ \\
\hline Wind direction & $29.7 \mathrm{~m}$ & wind vane & $5 \mathrm{~Hz}$ \\
\hline $\begin{array}{l}3 \text { axis wind speed } \\
\text { and temperature }\end{array}$ & $\begin{array}{l}46.6 \mathrm{~m}(42.3 \mathrm{~m} \\
\text { from } 12.5 .99)\end{array}$ & ultrasonic anemometer & $20 \mathrm{~Hz}$ \\
\hline Air temperature & $10.0 \mathrm{~m}$ & Pt 100 & 30 min mean \\
\hline $\begin{array}{l}\text { Temperature } \\
\text { difference }\end{array}$ & $49.8 \mathrm{~m}-10.0 \mathrm{~m}$ & Pt 500 & 30 min mean \\
\hline Sea temperature & about $-2 \mathrm{~m}$ & Pt 100 & 30 min mean \\
\hline Sea level & & $\begin{array}{l}\text { DHI AWR201 acoustic } \\
\text { wave recorder }\end{array}$ & $8 \mathrm{~Hz}$ \\
\hline Sea current & & GMI current meter & $8 \mathrm{~Hz}$ \\
\hline
\end{tabular}


Table 2: Synoptic stations used for estimating the upwind air temperature over land

\begin{tabular}{|l|l|l|l|l|}
\hline & latitude & longitude & height asl & direction from \\
\hline Glücksburg & $54^{\circ} 49^{\prime}$ & $09^{\circ} 30^{\prime}$ & $27 \mathrm{~m}$ & $281^{\circ}$ \\
\hline Olpenitz & $54^{\circ} 40^{\prime}$ & $10^{\circ} 02^{\prime}$ & $4 \mathrm{~m}$ & $279^{\circ}$ \\
\hline Kiel-Holtenau & $54^{\circ} 22^{\prime}$ & $10^{\circ} 08^{\prime}$ & $27 \mathrm{~m}$ & $256^{\circ}$ \\
\hline Lübeck-Blankensee & $53^{\circ} 48^{\prime}$ & $10^{\circ} 42^{\prime}$ & $14 \mathrm{~m}$ & $221^{\circ}$ \\
\hline Boltenhagen & $54^{\circ} 00^{\prime}$ & $11^{\circ} 11^{\prime}$ & $15 \mathrm{~m}$ & $210^{\circ}$ \\
\hline Laage & $53^{\circ} 55^{\prime}$ & $12^{\circ} 17^{\prime}$ & $40 \mathrm{~m}$ & $150^{\circ}$ \\
\hline Barth & $54^{\circ} 20^{\prime}$ & $12^{\circ} 43^{\prime}$ & $7 \mathrm{~m}$ & $112^{\circ}$ \\
\hline
\end{tabular}

